\title{
The Relationship Between Problematic Video Gaming, Problematic Facebook Use, and Self-Control Dimensions Among Female and Male Gamers
}

\author{
Andrzej Cudo', Tomasz Misiuro' ${ }^{2}$ Mark D. Griffiths ${ }^{3}$, and Małgorzata Torój ${ }^{4}$ \\ 'Department of Experimental Psychology, The John Paul II Catholic University of Lublin, al. Racławickie 14, 20-950, Lublin, Poland \\ 2 Department of Psychological Research Methodology, The University of Zielona Góra, Licealna 9/9, 65-417, Zielona Góra, Poland \\ ${ }^{3}$ International Gaming Research Unit, Nottingham Trent University, 50 Shakespeare St, Nottingham NG1 4FQ, United Kingdom \\ ${ }^{4}$ Department of Emotion and Motivation Psychology, The John Paul II Catholic University of Lublin, al. Racławickie 14, 20-950 Lublin, Poland
}

\section{KEYWORDS}

problematic Facebook use problematic video gaming self-control

female gamers

male gamers
ABSTRACT

The development of new technology has contributed to changes in everyday functioning. However, one possible negative aspect of new technologies is their problematic, uncontrolled use. Dysfunctional self-control is a critical aspect of problematic behavior. Consequently, the present research investigated the relationship between problematic video gaming (PVG), problematic Facebook use (PFU), and self-control dimensions among female and male gamers. The study comprised 830 videogame players ( 350 female gamers) aged from 15 to 31 years. PFU was assessed using the Facebook Intrusion Scale, and PVG was assessed using the Problem Video Game Playing Questionnaire. Self-control dimensions were assessed using the 50-item Nowy Arkusz Samowiedzy (SelfKnowledge New Sheet; NAS-50). Findings showed that lower goal maintenance was associated with higher PFU, whereas lower initiative and persistence was associated with higher PVG among both groups. Additionally, there was a negative association between inhibition and adjournment and problematic behaviors among male gamers. In contrast, PFU was associated inhibition and adjournment among female gamers. The findings demonstrate the difference between both genders in the relationship between PVG and self-control. These findings enable a better understanding of the relationship between problematic behaviors and self-control among gamers and the differences between female and male gamers.

\section{INTRODUCTION}

The development of new technologies has contributed to a change in human functioning (Botella et al., 2012; Hofmann, Reinecke \& Meier, 2017; Lee \& Daiute, 2019). The internet and mobile devices have become an indispensable part of daily life, enabling contact with other individuals both personally and professionally. Many individuals cannot imagine the possibility of functioning without such technologies nowadays (Statista, 2017, 2019). Consequently, social media use has become important in facilitating and maintaining virtual interpersonal relationships. Moreover, computers, laptops, tablets, and smartphones have become platforms for both work and entertainment. Despite the many positive developments related to new technologies, there are also potential negative effects associated with problematic video gaming
(PVG) and problematic social media use among a minority of individuals. Consequently, many scholars are interested in the subject of problematic behavior and have tried to understand their underlying mechanisms.

According to Social Media Update 2019 (Pew Research Center, 2019), Facebook is the most popular social networking platform in the United States compared to Instagram, Pinterest, LinkedIn, and Twitter. Almost 70\% of adults in the United States use Facebook, and $51 \%$ of them use this platform several time a day. In Poland (where the

Corresponding author: Andrzej Cudo, Department of Experimental Psychology, The John Paul II Catholic University of Lublin, al. Racławickie 14, 20-950 Lublin, Poland.E-mail:andrew.cudo@gmail.com 
present study was carried out), recent statistics (We Are Social Inc., 2020) show that $89 \%$ of internet users aged 16 to 64 years have used Facebook in the past month and that this is the most popular social networking platform. Additionally, $96.2 \%$ active Facebook users access the platform via mobile. Videogames are also very popular. According to a report from the Entertainment Software Association (ESA), 65\% of the American population play videogames. According to the ESA, the average age of gamers is now 33 years, and $46 \%$ of gamers are female (ESA, 2019). Additionally, female gamers from 18 to 34 years old primarily play casual games and action games, and most often play such games on their smartphone. Male gamers at that age are primarily play action games, shooter games and sports games, and most often play such games on their game console (ESA, 2019). In Poland, 76\% of individuals from 15 to 65 years old play videogames and $47 \%$ of gamers are female. Like the United States, female gamers most often play games on smartphones or tablets, whereas male gamers most often play games on a game console (Polish Gamers Observatory [PGO], 2019). Additionally, action games were one of the most popular game genres regardless of the device except for playing on social networking websites where card games, logic games, and board games were the most popular (PGO, 2019). Taking into account the number of users and the high popularity of Facebook and videogames, it is essential to better understand the influence these activities have on individuals' behavior.

\section{Problematic Facebook Use and Problematic Video Gaming}

Problematic Facebook use (PFU) is defined as an excessive engagement in Facebook activities causing problems in everyday social functioning (Elphinston \& Noller, 2011). This is close to the definition of problematic social networking site (SNS) use proposed by Andreassen and Pallesen (2014) who describe such behavior as "being overly concerned about SNSs, to be driven by a strong motivation to log on to or use SNSs, and devote so much time and effort to SNSs that it impairs other social activities, studies/job, interpersonal relationships, and/or psychological health and well-being" (p. 4054). However, the diagnostic criteria for this type of problematic behavior are not included in any official classification.

Problematic video gaming has become a major social problem for a minority of individuals, and it is included in the latest (fifth) edition of the Diagnostic and Statistical Manual of Mental Disorder (DSM-5) as Internet Gaming Disorder (IGD; American Psychiatric Association, 2013). Gaming disorder has also been included in the latest, 11th revision of the International Classification of Diseases (ICD-11) which defines the behavior as "characterized by a pattern of persistent or recurrent gaming behavior (...) manifested by: 1) impaired control over gaming $(. .) ;$.2 ) increasing priority given to gaming to the extent that gaming takes precedence over other life interests and daily activities; and 3) continuation or escalation of gaming despite the occurrence of negative consequences" (World Health Organization, 2018). Further to this, Griffiths $(1996,2005,2019)$ has posited the following symptoms of behavioral addiction in relation to both videogames and social me- dia use: salience, mood modification, tolerance, withdrawal, conflict, and relapse. Griffiths asserts that in order to recognize such behaviors as addictions, all the six listed consequences must occur. However, problematic behavior may still be present if only some of these consequences occur. Additionally, Andreassen et al. (2012), and Brailovskaia and Margraf (2017) adopted the criteria developed by Griffiths (1996, 2005, 2019) with respect to problematic Facebook use.

According to the Interaction of Person-Affect-CognitionExecution (I-PACE) model (Brand et al., 2016, 2019), PVG and PFU may be viewed as a subtype of addictive behavior (see Brand et al., 2019). According to the I-PACE model, specific predisposing behavioral variables such as specific needs, motives, and values, in conjunction with general predisposing variables such genetics, early childhood experiences, psychopathology, coping strategies, and temperamental features, may condition a specific type of problematic behavior. In this context, Pontes (2017) showed that problematic SNS use and PVG are positively correlated to one another and may simultaneously influence overall psychological health. Additionally, Cudo et al. (2020b) found a similar relationship between PFU and PVG. However, they also reported different predictors for both problematic behaviors. It should be also noted that PFU and PVG may be associated with similar negative outcomes such as depression, anxiety, insomnia, and suicide-related outcomes (Brailovskaia et al., 2019a, 2019b; Brailovskaia et al., 2020; Kuss \& Griffiths, 2012; Twenge et al., 2018; Van Rooij et al., 2014).

According to the I-PACE model, Brand et al. (2019) described the transition from differentiating environmental aspects (e.g., delivery of reward options, intermittent reinforcement, availability/accessibility, affordability), through individual reactions (e.g., specific behavior, rewarding experiences, development of cue-reactivity, development of implicit cognition), to consequences of repeated specific behaviors over time (e.g., habits and compulsions, continuing behavior despite experiencing negative consequences, neural adaptation). Consequently, they postulated that interactions between individuals' predisposing variables and specific situational variables can result in problematic behaviors such as PFU and PVG. Additionally, self-regulation/self-directedness, as well as general inhibitory control, moderate the relationship between affective and cognitive responses to external or internal triggers associated with specific behavior and decisions to involve in this behavior (Brand et al., 2019). Consequently, self-control can be a significant phenomenon associated with the predisposition to problematic behavior. The importance of self-control is even greater because previous studies have shown a positive relationship between self-control and success in various dimensions of life such as work, school, adjustment, interpersonal relationships, and management of problem desires (De Ridder et al., 2012). Consequently, considering that previous studies have mostly focused on single aspects of selfcontrol (Błachnio \& Przepiorka, 2016; Kim et al., 2008; Khang et al., 2013; Mills \& Allen, 2020; Şalvarlı \& Griffiths, 2019) despite its multidimensionality (see Kotabe \& Hofmann, 2015; Nęcka et al., 2016), further studies are needed to help explain the types of interdependence between various self-control dimensions and problematic behavior such as PFU and PVG. 


\section{Self-Control}

Self-control has been defined as "an act of self-control by which the self alters its own behavioral patterns so as to prevent or inhibit its dominant response" (Muraven \& Baumeister, 2000, p. 247). Additionally, self-control may also be defined as "the ability to override or change one's inner responses, as well as to interrupt undesired behavioral tendencies (such as impulses) and refrain from acting on them" (Tangney et al., 2004, p. 274). Self-control may also be understood as the ability to behave in relative autonomy from external pressures, automatisms, or impulses (Nęcka, 2015; Nęcka et al., 2016, 2019). Nęcka pointed out that self-control appears through the delay of gratification, inhibition of prepotent responses, emotion regulation, and adequate adaptation to a social environment (Nęcka, 2015; Nęcka et al., 2019).

Kotabe and Hofmann (2015) developed the integrative self-control theory (SCT), in which self-control involves an intrapsychic conflict between desire and a higher-order goal. In this context, desire is considered as a psychological driving force which is rooted in congenital or learned need states (Kotabe \& Hofmann, 2015). In contrast, higherorder goals are understood as intentional and declarative expectations associated with long-term benefits. Based on the SCT, if the desire and higher-order goals are co-activated, there occurs a desire-higher order goals conflict that turns desire into temptation and the higher-order goal into a self-control goal (Kotabe \& Hofmann, 2015). The D-G conflict provides the trigger to self-control exertion processes by activation control motivation, which is defined as the aspiration to control desire. In addition to this type of motivation, control capacity, described as non-motivational cognitive resources such as directed attention, inhibitory capacity, and working memory capacity, is also engaged in control desire. Consequently, the control motivation and control capacity determine the control effort, which is described as using the available stock of control capacity actively and effectively to resist the desire. However, desire strength, perceived skill, and competing goals moderate the potential control effort (Kotabe \& Hofmann, 2015, 2016). This competition between desire and control effort leads to a choice of behavior associated with desire or self-control goals. However, the SCT also includes enactment constraints as environmental factors which may constrain the range of available behavioral options to the higher-order goal or desire enactment (Kotabe \& Hofmann, 2015). Additionally, the SCT indicates four types of self-control failures: (a) desire-based control failure when desire is so strong that the individual does not notice their higher-order goals; (b) higher-order goal-based failure when the higher-order goal is neglected, which allows desire to activate fully; (c) control motivation-based failure when control motivation is insufficient; and (d) control capacity-based failures when control capacity is insufficient (Kotabe \& Hofmann, 2015).

Nęcka et al. (2016), based on the SCT (Kotabe \& Hofmann, 2015), pointed out that self-control consists of the following five elements: (a) initiative and persistence, (b) proactive control, (c) switching and flexibility, (d) inhibition and adjournment, and (e) goal maintenance. Initiative and persistence are motivational aspects of self-control, which are associated with the ability of efficient motivation induction and persistence in achieving a higher-order goal. Proactive control is associated with the ability to undertake necessary arrangements and foresee possible obstacles in goal-directed behaviors. Switching and flexibility is the ability to switch between tasks and actions in order to avoid perseverance or learned irrelevance. Inhibition and adjournment are associated with suppressed or delayed unwanted or improper actions that may contribute to the failure of goal-directed behavior. Also, this self-control dimension is defined as the ability to inhibit emotional reactions and refrain from immediate, impulsive behavior (Nęcka et al., 2019). Goal maintenance comprises remembering plans and objectives, in particular as regards the importance of time schedules. Additionally, this is the ability to keep intentions and long-term plans in mind (Nęcka et al., 2019).

Taking into account the SCT (Kotabe \& Hofmann, 2015) and previous research (Lindner et al., 2015; Maloney et al., 2012; Nęcka et al., 2016), it should be noted that self-control is not a one-dimensional construct but has many dimensions. However, previous research on PFU and PVG is mostly based on a one-dimensional approach to self-control (Błachnio \& Przepiorka, 2016) or analyzed in relation to one aspect of self-control only, such as procrastination (Przepiorka et al., 2016; Yeh et al., 2017) or impulsivity (for reviews, see Şalvarlı \& Griffiths, 2019; Sindermann et al., 2020). In this context, procrastination may be understood as a "self-regulatory failure of not exerting self-control necessary for task engagement" (Sirois \& Pychyl, 2013, p. 116) and may involve control motivation-based failure, low initiative and persistence, and low goal maintenance (see Kotabe \& Hofmann, 2015; Nęcka et al., 2016). Additionally, impulsivity, characterized by a tendency to act spontaneously without deliberation (Carver, 2005), may be associated with desire-based control failure and low inhibition and adjournment (see Kotabe \& Hofmann, 2015; Nęcka et al., 2016). Taking the above together, it is important to verify the relationship between problematic behaviors and various dimensions of self-control, taking into account the inter-relationship between these dimensions. This would allow for a more accurate understanding of which deficits in self-control are supportive of problematic behaviors. However, to better understand this relationship, it should be considered how the structure of media can make demands on self-control.

\section{Self-Control and Media Use}

Hofmann et al. (2017) postulated that three media and communication affordances may contribute to their temptation potential: immediate gratifications, habitual usage, and ubiquitous availability. Consequently, resisting the temptation to use social media and gaming is a big challenge for an individual's self-control. Taking into account possible strong and positive automatic affective reactions to media content, successful self-control of media use desires may be more difficult (Hofmann et al., 2012; Hofmann et al., 2017). Additionally, strong automatic approach reactions concerning media content may contribute to habitual media use, especially when considering that gratification associated with the use of media is possible almost everywhere via smartphones, tablets, smartwatches, and so forth. Consequently, Hofmann et al. (2017) observed that the ubiquity of media content may provide an increase the frequency of situations in which self-control 
involved in the resolution of goal conflicts between goal-directed daily activities and media temptations. In this context, it should be noted that external stimuli associated with media such as advertisements and push notification messages may also contribute to self-control failure (Cudo et al. 2019; Kim et al., 2016; Starcke et al., 2018; Turel et al., 2014).

In this context, Du et al. (2019) showed that social media self-control failure is associated with immediately satisfying gratifications related to using social media, such as entertainment gratifications, social gratifications, and information-seeking gratifications. They also found that this type of self-control failure is associated with the tendency to think frequently and intensively about online activities as well as the tendency for automatic and habitual activity associated with checking social media. Supportively, Griffiths (2018a) pointed out that habitual social media use may be associated with factors such as unpredictable rewards, smartphone sounds and vibrations, fear of missing out, social affirmation and validation, social connection, reciprocal liking, social competition, and psychological investment. Taking into account the relationship between media and self-control described by Hofmann et al. (2017) and the SCT (Kotabe \& Hofmann, 2015), unpredictable rewards, smartphone sounds and vibrations, and fear of missing out associated with social media may be a big challenge for self-control. For example, individuals may have difficulties in refraining from answering a message when they hear the message signal, even though they need to do something more important. In this situation, they have to engage their self-control resources to refrain from answering the message. However, in some situations, unpredictable rewards, smartphone sounds and vibrations, and fear of missing out may lead to self-control failure in contact with social media. It also should be noted that low self-control, habitual Facebook checking, and high enjoyment of Facebook use were associated with using Facebook for procrastination (Meier et al., 2016)

Similar to social media use, playing videogames may increase the requirements for self-control. King et al. (2010a) outlined a five-feature model of videogame structural characteristics comprising (a) social features, (b) manipulation and control features, (c) narrative and identity features, (d) reward and punishment features, and (e) presentation features. Taking into account the influence of media on self-control (Hofmann et al., 2017), some of these structural characteristics can directly contribute to self-control failure, especially reward and punishment features, which are associated with different types of rewards received in the game, from quick rewards (e.g., experience points, bonuses, coins) to meta-game rewards (e.g., Xbox 360 achievement points, best gamer rankings; see King et al., 2010a). Additionally, other structural characteristics may also contribute to habitual videogame usage (see Griffiths \& Nuyens, 2017), such as the inclusion of gambling elements (e.g., loot boxes) in computer games (Drummond \& Sauer, 2018; Griffiths, 2018b, 2018c). Moreover, previous research (Hartmann \& Klimmt, 2006; Lopez-Fernandez et al., 2019; McLean \& Griffiths, 2019) also showed that female gamers prefer different game features to male gamers. Consequently, self-control may have different challenges among female and male gamer groups. It should also be noted that videogames are currently available at any time on various devices such as computers, tablets, smartphones, and consoles. Taken together, characteristics associated with videogame structure as well as SNSs may be a challenge for self-control. Consequently, individuals who use SNSs and videogames should have a sufficient level of self-control to prevent functional use of these media from becoming problematic. For this reason, it is important to identify self-control dimensions, the dysfunctions of which can contribute to problematic behavior.

\section{Self-Control and Problematic Behaviors}

In the social media context, Błachnio and Przepiorka (2016) reported a negative relationship between self-control, failure-related action orientation (i.e., ability to disengage from undesirable experiences and failure), and PFU. Cudo et al. (2020a) replicated that study, additionally taking into account the relationship between self-control and control dimensions, and the division of self-control into impulsivity and restraint (see also Carver, 2005; Lindner et al., 2015; Maloney et al., 2012). They showed that PFU was positively associated with impulsivity as well as performance-related action orientation. In this context, impulsivity is characterized by a tendency to act spontaneously without deliberation (Carver, 2005) and performance-related action orientation is defined as the ability to stay focused on self-initiated and pleasant activities (Kuhl, 1994). However, they found no relationship between PFU and the aspect of self-control associated with restraint, which is characterized by a tendency to be deliberative or disciplined and engage in effortful control (Carver, 2005). Additionally, the previous study (Turel et al., 2014; Turel \& Qahri-Saremi, 2016) showed that PFU is primarily associated with a dysfunction of the impulsive system rather than the reflective system. According to the reflectiveimpulsive theory of the mind (Hofmann et al., 2009), the impulsive system is responsible for generating impulsive behavior, whereas the reflective system serves regulatory goals and is responsible for higherorder mental operations. Consequently, these results (Turel et al., 2014; Turel \& Qahri-Saremi, 2016) are in line with the those of research by Cudo et al. (2020a). Additionally, Przepiorka et al. (2016) reported that procrastination was a predictor of PFU. In this context, Ryan et al. (2016) postulated that procrastination is a predictor of two of the three types of PFU: low social engagement-high browsing and low social engagement-moderate gaming. Consequently, taking into account the association between procrastination and self-control (Sirois \& Pychyl, 2013; Chen et al., 2019; Zhao et al., 2019), it can be assumed that PFU is probably associated with control motivation-based failure, low initiative and persistence, and low goal maintenance (see Kotabe \& Hofmann, 2015; Nęcka et al., 2016). Additionally, considering the association between impulsivity and PFU (Sindermann et al., 2020; Cudo et al., 2020a), it can be assumed that this type of problematic behavior may be associated with desire-based control failure and low inhibition and adjournment (see Kotabe \& Hofmann, 2015; Nęcka et al., 2016). However, the relationship between restraint (Cudo et al., 2020a), the reflective system (Turel et al., 2014; Turel \& Qahri-Saremi, 2016), and PFU has not been found. Consequently, taking into account the fact that the reflective system is associated with making deliberate 
judgments and evaluations and putting together strategic action plans for goal pursuit (Hofmann et al., 2009), these results may indicate that this problematic behavior is probably not associated with proactive control, which is characterized as the ability to undertake necessary arrangements and foresee possible obstacles in goal-directed behaviors (see Nęcka et al., 2016).

For PVG the context, Kim et al. (2008) reported that low selfcontrol was a predictor of PVG. Additionally, Khang et al. (2013) reported that low self-control was a predictor of PVG, problematic internet use, and problematic mobile phone use. Similarly, Mills and Allen (2020) found a relationship between low self-control and PVG, weekly playtime, and less adaptive videogame playing motivations such as introjected regulation, amotivation, and integrated regulation. In this context, introjected regulation is associated with internal pressures (e.g., guilt, shame, obligation) to engage in videogame playing, whereas amotivation is associated with engaging in videogame playing despite the lack of volition to do so. Additionally, integrated regulation is characterized as a conviction that the sense of self is expressed via involvement in videogame playing (Mills \& Allen, 2020; Ryan \& Deci, 2017). However, some studies have shown no correlation between selfcontrol and PVG (Mehroof \& Griffiths, 2010).

Additionally, previous PVG studies showed that impulsivitycharacterized as a tendency to act spontaneously without deliberation (Carver, 2005) - is associated with this type of problematic behavior (Gervasi et al., 2017; Şalvarlı \& Griffiths, 2019). It has also been shown that dysfunctional impulsivity has a positive relationship with PVG, game engagement, and frequency of play (Blinka et al., 2016). Additionally, Bailey et al. (2013) reported that PVG and playing firstperson shooter (FPS) games were positively associated with greater impulsivity. There was also a positive relationship between impulsivity and the interaction between game hours and this type of problematic behavior for FPS games. In this context, it should be noted that FPS games are a specific type of action videogames which are associated with PVG (Cudo et al., 2018; 2020b). Moreover, Nuyens et al. (2016) showed that only cognitive impulsivity (characterized as difficulties in staying focused on a task) was positively associated with PVG especially in relation to preoccupation and immersion However, there was no relationship between motor impulsivity (acting on the spur of the moment), non-planning impulsivity (difficulties to take on a complicated task) and PVG.

It should also be noted that Yeh et al. (2017) reported that gamers who fulfilled the criteria for IGD presented higher impulsivity and procrastination compared with gamers without an IGD diagnosis. However, Nuyens et al. (2016) considered the different dimensions of impulsivity (self-description and experimental) and they showed that PVG was not related to all dimensions of impulsivity. There was no relationship between positive urgency, negative urgency, lack of premeditation, lack of perseverance, sensation seeking, motor impulsivity, non-planning impulsivity, and PVG. However, PVG was positively related with cognitive impulsivity and negatively with mean waiting time during the first half of the single key impulsivity experimental task (Nuyens et al., 2016). Similarly, Rømer Thomsen et al. (2018) reported no correlations between PVG and every impulsivity dimension assessed by the Impulsive Behavior Scale (Lynam et al., 2006). Additionally, Deleuze et al. (2017) found no differences between problematic and non-PVG groups in relation to impulsivity traits. Taken together, the results presented, similar to PFU, indicate that PVG appears to be associated with self-control failure (see Kotabe \& Hofmann, 2015). Self-control failure may be associated with low inhibition and adjournment, low initiative and persistence and low goal maintenance. It should be noted that the relationship between one-dimensional impulsivity and PVG is well described (Şalvarlı \& Griffiths, 2019). However, previous research (Nuyens et al., 2016; Rømer Thomsen et al., 2018) showed that when different dimensions of impulsivity are taken into account, the results of relationship analysis between PVG and impulsivity dimensions are not consistent.

Additionally, in case of the self-control dimension associated with switching and flexibility (characterized as the ability to switch between tasks and actions in order to avoid perseverance or learned irrelevance; Nęcka et al., 2016), it is probably closely related to media multitasking (characterized as the ability to do multiple tasks simultaneously or a tendency to switch between different tasks; Ophir et al., 2009). In this context, previous research has shown no relationships between media multitasking and PFU (Błachnio \& Przepiorka, 2016; Wang et al., 2019) or PVG (Wang et al., 2019). Consequently, it is assumed that the self-control dimension associated with switching and flexibility is not associated with the PFU or PVG.

\section{The Present Study}

Previous studies demonstrated the importance of the association between low self-control and problematic behaviors such as PFU and PVG. However, to date, the relationships between these two problematic behaviors and the different self-control dimensions have not been thoroughly investigated. This is important because, on the basis of previous research, it can be assumed that individuals with problematic behavior may have deficits in various dimensions of self-control (see Cudo et al., 2020a; Nuyens et al., 2016; Turel et al., 2014; Turel \& Qahri-Saremi, 2016; Yeh et al., 2017). Taking into account previous findings showing a relationship between procrastination, impulsivity and both problematic behaviors, and incorporating the SCT (Kotabe \& Hofmann, 2015), the association between low inhibition and adjournment, low initiative and persistence, low goal maintenance (see Nęcka et al., 2016), and PFU and PVG should be considered further.

This assumption may also be supported by research indicating that immediate gratifications, habitual usage, and ubiquitous availability associated with Facebook and videogame use can be challenging for self-control (Du et al., 2019; Hofmann et al., 2017; King et al., 2010a). Additionally, on the basis of previous studies (Cudo et al., 2020a; Turel et al., 2014; Turel \& Qahri-Saremi, 2016), it is assumed that both problematic behaviors are probably not associated with proactive control. Similarly, considering the lack of relationship between multitasking and PFU (Błachnio \& Przepiorka, 2016; Wang et al., 2019) as well as PVG (Wang et al., 2019), it is cautiously concluded that there is no relationship between both problematic behaviors and the self-control 
dimension associated with switching and flexibility. In addition, considering the differences in the prevalence of PFU (Andreassen et al., 2016; Cudo et al., 2020b; Marino et al., 2018) and PVG (Andreassen et al., 2016; Cudo et al., 2020b; Wittek et al., 2016) between males and females, it should also be considered whether the pattern of selfcontrol deficits is similar for both genders. Consequently, taking into account the theoretical considerations and previous findings, the following hypotheses were formulated:

$\mathrm{H} 1$ : Lower goal maintenance is associated with both PFU and PVG.

$\mathrm{H} 2$ : There is a negative relationship between inhibition and adjournment and both PFU and PVG.

H3: Lower initiative and persistence are associated with both PFU and PVG.

H4: There is no relationship between PFU and PVG and the selfcontrol dimension associated with switching and flexibility.

H5: There is no relationship between PFU and PVG and proactive control.

H6. The relationship between both PFU and PVG and selfcontrol dimensions is different among males compared to females.

\section{METHODS}

\section{Participants}

The study comprised 830 videogame players (350 female gamers) aged from 15 to 31 years $(M=18.57$ years, $S D=2.47)$ selected from 1979 individuals who completed a pen-and-paper questionnaire. The criteria for inclusion were based on whether the participants are currently active videogame players. More specifically, those who self-declared as playing videogames at least three hours a week in the past year were selected for the data analysis. The female gamers' ages ranged from 16 to 31 years $(M=19.32 ; S D=2.54)$. The male gamers' ages ranged from 15 to 30 years $(M=18.03 ; S D=2.27)$. Participants were students of Polish high schools $(N=548)$ and universities $(N$ = 282) from four voivodeships (administrative regions) of Poland (i.e., Małopolskie, Lubelskie, Lubuskie and Podkarpackie). The participants were approached in their classrooms and asked to complete a pen-and-paper questionnaire after the researcher presented them with information about the study. All participants were volunteers, and they received no monetary reward. Also, participants were informed that their responses would be anonymous and confidential. The study was conducted in accordance with the Declaration of Helsinki and approved by the Institute of Psychology's Ethical Committee of the research team's university.

\section{Materials}

\section{PROBLEMATIC FACEBOOK USE}

The Facebook Intrusion Scale (Elphinston \& Noller, 2011) includes eight items (e.g. "I often think about Facebook when I am not using it") to which answers are given on a seven-point scale, from 1 (strongly disagree), to 7 (strongly agree). Higher scores reflect a greater intensity of PFU. The questionnaire had good psychometric properties, with Cronbach's a equal to .84 in the present study. The scale has also been used in studies designed to investigate PFU in Poland (Błachnio \& Przepiórka, 2018; Cudo et al. 2020b) and different countries such as China, Greece, Israel, Italy, Romania, Turkey, and the USA (Błachnio et al., 2016b).

\section{PROBLEMATIC VIDEOGAME PLAYING}

The Problem Videogame Playing Questionnaire (Tejeiro et al., 2016), which was adapted into Polish, comprises nine statements (e.g., "When I can't use the videogames I get restless or irritable") rated by participants using a dichotomous (yes/no) scale. A greater number of positive responses provided by a participant corresponds with stronger PVG. Because of its high clinical accuracy, the questionnaire is one of the best tools currently applied in research into IGD (King et al., 2013). The scale has acceptable psychometric properties, with Cronbach's $\alpha$ of .61 in the present study. The original version of Problem Videogame Playing Questionnaire correlated with the frequency of gaming $(r=.48)$, with mean gaming time per session $(r=.44)$, and with longest gaming sessions ( $r=.47$; Tejeiro et al., 2016). The scale has been used in previous PVG studies in Poland (Cudo et al., 2018; Cudo et al. 2020b; Cudo, Kopiś \& ZabielskaMendyk, 2019).

\section{SELF-CONTROL}

The Self-Knowledge New Sheet (Nowy Arkusz Samowiedzy, NAS-50) is a 50-item self-report scale assessing self-control developed by Nęcka et al. (2016). The scale is based on the SCT (Kotabe \& Hofmann, 2015) and answers to its items are given on a five-point scale, from 1 (certainly not) to 5 (certainly). The scale comprises five subscales: initiative and persistence (IP; e.g., "I'm not in the habit of postponing work until the next day"), proactive control (PC; e.g. "When I have a lot of work to do, I make a detailed plan of this work"), switching and flexibility (SF; e.g. "I can easily follow a conversation between several people"), inhibition and adjournment (IA; e.g. "Sometimes I do some impulsive things before I think about it" - reverse-scored question), and goal maintenance (GM; e.g. "I forget the unfinished activities" - reverse-scored question). In the present study, Cronbach $\alpha$ values for the subscales were 0.68 (GM), .72 (PC), .81 (IP), .69 (SF), and .74 (IA). For each subscale, the minimum score is 10 , and the maximum score is 50 . Higher scores indicate higher levels of a given aspect of self-control.

\section{DEMOGRAPHICS AND WEEKLY HOURS SPENT USING FACEBOOK AND GAMING}

Questions were also asked relating to demographic information (i.e., age, gender, education). Additionally, individuals answered the question whether they were currently using Facebook (Yes/No) and whether they had played computer games during the past year (Yes/No). Questions were also asked relating to the number of hours spent per week using Facebook and playing videogames. In these 
questions, individuals had to write down the time spent on these activities in hours.

\section{Statistical Analysis}

The statistical calculations were conducted using the statistical software IBM SPSS version 23 for descriptive statistics and correlation analysis, and Stata 14 with medsem.ado package (Mehmetoglu, 2018) for structural equation analysis and mediation analysis. Descriptive statistics were presented in the form of arithmetic means and SDs. Spearman's rank correlation coefficients were calculated to determine relationships between the analyzed variables. In order to assess the differences between female and male gamers and taking into account the non-normal distribution of some variables, the Mann-Whitney two-sample tests (Mann \& Whitney, 1947) were applied. Additionally, descriptive statistics such as means, SDs, median $(\mathrm{Me})$, and quartile deviation $(Q)$ were presented for both groups. The magnitude of differences was measured as the $\eta^{2}$ effect size (Fritz et al., 2012).

In order to examine the relationship between PFU, PVG, and selfcontrol dimensions in the sample of female and male gamers, structural equation analysis was conducted. Taking previous research into account (Billieux et al., 2015; Błachnio \& Przepiorka, 2016; Cudo et al., 2018; 2020a; Kim et al., 2016), a model with age and self-control dimensions as predictors of PFU and PVG was developed. Additionally, age and the relationship of self-control with Facebook hours and videogame hours were included. Structural equation analysis was based on the maximum likelihood method, applied to estimate a structural model for of dependence between variables. However, violation of multivariate normal distribution was taken into account among both female gamers (Doornik-Hansen omnibus test: $\chi^{2}(d f=20)=1136.07$; $p<.001$, Henze-Zirkler's consistent test: $\chi^{2}(d f=1)=333.16 ; p<.001$, Mardia's multivariate kurtosis test: $\chi^{2}(d f=1)=261.44 ; p<.001$, and Mardia's multivariate skewness test: $\left.\chi^{2}(d f=220)=1240.20 ; p<.001\right)$ and male gamers (Doornik-Hansen omnibus test: $\chi^{2}(d f=20)=$ 1641.67; $p<.001$, Henze-Zirkler's consistent test: $\chi^{2}(d f=1)=1351.58$; $p<.001$, Mardia's multivariate kurtosis test: $\chi^{2}(d f=1)=374.96 ; p<$ .001 , and Mardia's multivariate skewness test: $\chi^{2}(d f=220)=1483.91 ; p$ $<0.001$ ), as well as the Sattora-Bentler adjustment (Satorra \& Bentler, 1994)

The $\chi^{2}, \chi^{2} / d f$, root mean square error of approximation (RMSEA), standardized root mean square residual (SRMR), comparative fit index (CFI), and Tucker-Lewis index (TLI) statistics were applied as measures of the model fit (Hu \& Bentler, 1999; Kline, 2011). Statistically insignificant $(p>.05) \chi^{2}$ values may suggest that the proposed model fits the dataset well. If the value of $\chi^{2} / d f$ ratio is lower than 2 , it suggests a good fit to the dataset. Likewise, values of RMSEA and SRMR lower than 0.05 show a good fit of the model. Values of CFI and TLI higher than 0.90 demonstrate the model fits the dataset well ( $\mathrm{Hu} \&$ Bentler, 1999; Kline, 2011).

Taking into account the I-PACE model (Brand et al., 2016; 2019), PFU and PVG were treated as subtypes of specific internet-use disorders, therefore, the models with and without the relationship between these two problematic behaviors were tested. Additionally, specific studies have postulated that the number of hours spent using Facebook is a predictor of PFU (Błachnio et al., 2016a; Brailovskaia et al., 2018), while other studies suggested that the number of hours spent using Facebook is the consequence of this type of problematic behavior (Turel, 2015; Turel et al., 2018). Analogous results were reported in studies examining the relationship between gaming time and the PVG (Columb et al., 2019; Griffiths, 2010; Kuss \& Griffiths, 2012; Mihara \& Higuchi, 2017; Triberti et al., 2018). Consequently, the models treating the Facebook hours and videogames hours as predictors or consequences of problematic behavior were compared. Taking into account previous studies (Cudo et al., 2020b), the present study also examined the relationship between time spent on Facebook and time spent playing videogames. Taking all the above configurations together, eight possible models were examined. On the basis of the conducted analyses, the model with the best fit to the data was selected.

In the next step, to examine potential regression weights of the differences between female $(n=350)$ and male gamers $(n=480)$, the Wald test (Wald, 1943) was conducted (Acock, 2013). Additionally, in order to analyze the mediation effects between self-control dimensions, hours spent on Facebook and gaming, and problematic behaviors, the Zhao et al. (2010) approach comprising the Monte Carlo method (5000 samples) to estimate standardized indirect effects with $95 \%$ confidence interval (Mehmetoglu, 2018) was used. The mediation effect was interpreted in accordance with Zhao et al.s (2010, p. 200) guidelines: (a) complementary mediation: indirect effect and direct effect both exist and point in the same direction; (b) competitive mediation: indirect effect and direct effect both exist and point in opposite directions; (c) indirect-only mediation: indirect effect exists, but no direct effect (full mediation); (d) direct-only non-mediation: direct effect exists, but no indirect effect; and (e) no-effect non-mediation: neither direct effect nor indirect effect exists.

\section{RESULTS}

The results showed a positive relationship between PFU and time spent per week dedicated to using Facebook $(\rho=.47, p<.001)$ as well as between PFU and PVG ( $\rho=.10, p=.003)$. Additionally, PFU correlated negatively with the self-control dimensions of goal maintenance $(\rho=-.23, p<.001)$, initiative and persistence $(\rho=-.15, p<$ $.001)$, and inhibition and adjournment $(\rho=-.28, p<.001)$. There was a negative relationship between PVG $(\rho=-.07, p=.045)$ and weekly amount of time spent using Facebook as well as between Facebook use and the self-control dimensions of goal maintenance $(\rho=-.17, p$ $<.001)$, initiative and persistence $(\rho=-.10, p=.006)$, and inhibition and adjournment $(\rho=-.23, p<.001)$. Problematic video gaming correlated negatively with the self-control dimensions of initiative and persistence $(\rho=-.21, p<.001)$ and inhibition and adjournment $(\rho$ $=-.10, p=.003)$, as well as age $(\rho=-.12 ; p<.001)$. Additionally, PVG was associated with the number of hours spent per week gaming $(\rho=.46, p<.001)$. The results also showed a positive relationship between goal maintenance $(\rho=.09 ; p=.012)$, inhibition and adjournment $(\rho=.08 ; p=.021)$, and weekly number of hours spent 


\begin{tabular}{|c|c|c|c|c|c|c|c|c|c|c|c|}
\hline Variables & $M$ & $S D$ & [1] & [2] & [3] & [4] & [5] & [6] & [7] & [8] & [9] \\
\hline [1] Problematic Facebook use & 20.74 & 9.37 & & & & & & & & & \\
\hline [2] Facebook number of hours per week & 27.34 & 29.79 & $0.47^{* * *}$ & & & & & & & & \\
\hline [3] Problematic video gaming & 2.33 & 1.76 & $0.10^{* *}$ & $-0.07^{\star}$ & & & & & & & \\
\hline [4] Game number of hours per week & 22.33 & 22.41 & -0.04 & 0.02 & $0.46^{* * *}$ & & & & & & \\
\hline [5] Self-control: goal maintenance & 38.28 & 5.93 & $-0.23^{* * *}$ & $-0.17^{* * *}$ & -0.03 & $0.09^{*}$ & & & & & \\
\hline [6] Self-control: proactive control & 35.24 & 5.82 & -0.05 & $-0.08^{*}$ & -0.06 & $-0.10^{* *}$ & $0.16^{* * *}$ & & & & \\
\hline [7] Self-control: initiative and persistence & 25.88 & 7.03 & $-0.15^{* * *}$ & $-0.10^{* *}$ & $-0.21^{* * *}$ & $--0.08^{*}$ & $0.27^{* * *}$ & $0.37^{* * *}$ & & & \\
\hline [8] Self-control: switching and flexibility & 37.02 & 5.48 & -0.04 & 0.05 & -0.03 & 0.01 & $0.09^{*}$ & $0.14^{* * *}$ & 0.02 & & \\
\hline [9] Self-control: inhibition and adjournment & 27.37 & 6.63 & $-0.28^{* * *}$ & $-0.23^{* * *}$ & $-0.10^{* *}$ & $0.08^{*}$ & $0.34^{* * *}$ & $0.07^{*}$ & $0.32^{* * *}$ & -0.05 & \\
\hline [10] Age & 18.57 & 2.47 & 0.01 & 0.04 & $-0.12^{* * *}$ & $-0.13^{* * *}$ & -0.05 & $0.11^{* *}$ & 0.05 & -0.04 & $0.07^{*}$ \\
\hline
\end{tabular}

$$
{ }^{* * *} p<.001,{ }^{* *} p<.01,{ }^{*} p<.05
$$

TABLE 2.

Differences Between Female $(n=350)$ and Male $(n=480)$ Gamers

\begin{tabular}{|c|c|c|c|c|c|c|c|c|c|c|c|c|}
\hline \multirow{2}{*}{ Variables } & \multicolumn{4}{|c|}{ Male gamers $(n=350)$} & \multicolumn{4}{|c|}{ Female gamers $(n=480)$} & \multirow{2}{*}{$U$} & \multirow{2}{*}{$z$} & \multirow{2}{*}{$p$} & \multirow{2}{*}{$\eta^{2}$} \\
\hline & $M$ & $S D$ & $M e$ & $Q$ & $M$ & $S D$ & $M e$ & $Q$ & & & & \\
\hline Problematic Facebook use & 19.93 & 8.84 & 18.00 & 6.00 & 21.86 & 9.95 & 21.00 & 7.50 & 75250.00 & -2.57 & .010 & .01 \\
\hline Facebook number of hours per week & 23.08 & 27.48 & 12.00 & 12.00 & 33.18 & 31.82 & 20.00 & 21.00 & 66753.50 & -5.06 & .001 & .03 \\
\hline Problematic video gaming & 2.64 & 1.78 & 2.00 & 1.50 & 1.90 & 1.66 & 1.50 & 1.00 & 62634.00 & -6.36 & .001 & .05 \\
\hline Gaming number of hours per week & 26.92 & 23.21 & 20.00 & 12.50 & 16.05 & 19.62 & 10.00 & 7.50 & 50865.50 & -9.74 & .001 & .11 \\
\hline \multirow{5}{*}{ 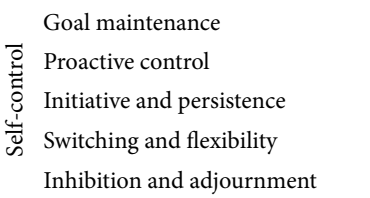 } & 39.14 & 5.72 & 40.00 & 3.50 & 37.11 & 6.03 & 37.50 & 4.00 & 66949.00 & -5.01 & .001 & .03 \\
\hline & 35.12 & 6.03 & 36.00 & 4.00 & 35.40 & 5.51 & 36.00 & 3.50 & 82874.50 & -0.33 & .741 & - \\
\hline & 25.83 & 6.90 & 26.00 & 4.50 & 25.96 & 7.21 & 26.00 & 5.00 & 83308.00 & -0.20 & .839 & - \\
\hline & 36.74 & 5.50 & 37.00 & 3.50 & 37.40 & 5.44 & 37.00 & 3.50 & 77629.50 & -1.87 & .061 & - \\
\hline & 28.71 & 6.55 & 29.00 & 4.50 & 25.54 & 6.31 & 26.00 & 4.50 & 61559.50 & -6.59 & .001 & .05 \\
\hline Age & 18.03 & 2.27 & 17.00 & 1.50 & 19.32 & 2.54 & 19.00 & 2.00 & 57177.50 & -7.98 & .001 & .08 \\
\hline
\end{tabular}

gaming. Additionally, the weekly number of hours spent gaming was negatively correlated with proactive control $(\rho=-.10, p=004)$, initiative and persistence $(\rho=-.08, p=.015)$, and age $(\rho=-.13 ; p<$ .001). Detailed results are presented in Table 1.

There was a significant difference between female and male gamers in PFU $\left(z=-2.57, p=.010, \eta^{2}=0.01\right)$, PVG $\left(z=-6.36, p<.001 ; \eta^{2}\right.$ $=.05)$, Facebook use hours $\left(z=-5.06, p<.001, \eta^{2}=.03\right)$, videogame playing hours $\left(z=-9.74, p<.001, \eta^{2}=.11\right)$, age $\left(z=-7.98, p<.001, \eta^{2}\right.$ $=.08)$, and self-control dimensions of goal maintenance $(z=-5.01, p$ $\left.<.001, \eta^{2}=.03\right)$, and inhibition and adjournment $(z=-6.59, p<.001$, $\left.\eta^{2}=.05\right)$. More specifically, female gamers reported greater PFU than male gamers. Contrastingly, male gamers reported greater PVG than female gamers. A parallel pattern of differences between female and male gamers was observed in the case of the weekly time spent using Facebook and videogames. Additionally, compared to female gamers, male gamers reported higher scores on the self-control dimensions of goal maintenance and inhibition and adjournment. However, the effect sizes of these differences were from small to medium. Detailed results are presented in Table 2.

In the next step, eight models were tested (see Table 3) and the results showed that only one model satisfied all fit indicators: $\chi^{2}(d f=4)=$ $2.32, p=.667, \chi^{2} / d f=0.58, \mathrm{CFI}=1.000, \mathrm{RMSEA}=0.001, \mathrm{SRMR}=0.007$, $\mathrm{TLI}=1.059$. This was a model assuming the relationship between PFU residual and PVG residual as well as between weekly Facebook hours residual and weekly videogame playing hours residual. This model also assumed that weekly Facebook hours and videogame playing hours were consequences of PFU and PVG, respectively. Consequently, the model is reported separately for female (see Figure 1) and male (see Figure 2) gamers. The model included covariance between self-control dimensions and age. However, due to the clarity of the model, they were excluded in Figures 1 and 2 (their values can be found in the Supplementary Materials).

For female gamers, the dimensions of self-control of goal maintenance $(\beta=-0.20, p<.001)$, and inhibition and adjournment $(\beta=$ $-0.23, p<.001$ ) were negatively and significantly associated with PFU. Additionally, there was a positive relationship between age and PFU $(\beta=0.11, p=.019)$. Initiative and persistence was only associated with PVG $(\beta=-0.23, p<.001)$. Furthermore, the number of weekly Facebook use hours was significantly associated with PFU ( $\beta=0.49, p$ $<.001)$. Additionally, there was a negative relationship between weekly Facebook hours and self-control dimensions of proactive control $(\beta=$ $-0.13, p=.019)$, and inhibition and adjournment $(\beta=-0.09, p=.040)$. Contrastingly, the weekly number of gaming hours was only associated with PVG ( $\beta=0.46, p<.001)$. Other paths were not statistically significant. Additionally, there was a positive correlation between residuals of weekly gaming hours and Facebook hours $(\mathrm{r}=.22 ; p=.015)$ whereas there was no correlation between residuals of both problematic behav- 


\begin{tabular}{|c|c|c|c|c|c|c|c|c|c|c|c|}
\hline & & & $\begin{array}{l}\text { TABLE } 3 . \\
\text { Fit Indices for }\end{array}$ & hot Mo & & & & & & & \\
\hline \multirow{2}{*}{$\begin{array}{l}\text { Model } \\
\text { number }\end{array}$} & \multirow{2}{*}{ Condition 1} & \multirow{2}{*}{ Condition 2} & \multirow{2}{*}{ Condition 3} & \multicolumn{8}{|c|}{ Fit indices } \\
\hline & & & & $\chi^{2}$ & $d f$ & $p<$ & $\chi^{2} / d f$ & CFI & RMSEA & SRMR & TLI \\
\hline 1 & \multirow{4}{*}{$\begin{array}{c}\text { Facebook hours } \\
\text { and game hours } \\
\text { as a predictor } \\
\text { of problematic } \\
\text { behavior }\end{array}$} & \multirow{2}{*}{$\begin{array}{l}\text { Facebook and game hours } \\
\text { residuals correlated }\end{array}$} & $\begin{array}{l}\text { PFU and PVG } \\
\text { residuals no } \\
\text { correlated }\end{array}$ & 26.12 & 6 & 0.001 & 4.35 & 0.953 & 0.090 & 0.017 & 0.527 \\
\hline 2 & & & $\begin{array}{c}\text { PFU and PVG } \\
\text { residuals correlated }\end{array}$ & 10.51 & 4 & 0.033 & 2.63 & 0.985 & 0.063 & 0.015 & 0.770 \\
\hline 3 & & \multirow{2}{*}{$\begin{array}{l}\text { Facebook and game hours } \\
\text { residuals no correlated }\end{array}$} & $\begin{array}{c}\text { PFU and PVG } \\
\text { residuals no } \\
\text { correlated }\end{array}$ & 37.42 & 8 & 0.001 & 4.68 & 0.931 & 0.094 & 0.025 & 0.481 \\
\hline 4 & & & $\begin{array}{c}\text { PFU and PVG } \\
\text { residuals correlated }\end{array}$ & 23.93 & 6 & 0.001 & 3.99 & 0.958 & 0.085 & 0.022 & 0.578 \\
\hline 5 & \multirow{4}{*}{$\begin{array}{c}\text { Facebook hours } \\
\text { and game hours } \\
\text { as a result of } \\
\text { problematic } \\
\text { behavior }\end{array}$} & \multirow{2}{*}{$\begin{array}{l}\text { Facebook and game hours } \\
\text { residuals correlated }\end{array}$} & $\begin{array}{c}\text { PFU and PVG } \\
\text { residuals no } \\
\text { correlated }\end{array}$ & 12.29 & 6 & 0.056 & 2.05 & 0.985 & 0.050 & 0.014 & 0.852 \\
\hline 6 & & & $\begin{array}{c}\text { PFU and PVG } \\
\text { residuals correlated }\end{array}$ & 2.32 & 4 & 0.677 & 0.58 & 1.000 & 0.001 & 0.007 & 1.059 \\
\hline 7 & & \multirow{2}{*}{$\begin{array}{l}\text { Facebook and game hours } \\
\text { residuals no correlated }\end{array}$} & $\begin{array}{c}\text { PFU and PVG } \\
\text { residuals no } \\
\text { correlated }\end{array}$ & 37.42 & 8 & 0.001 & 4.68 & 0.931 & 0.094 & 0.025 & 0.481 \\
\hline 8 & & & $\begin{array}{c}\text { PFU and PVG } \\
\text { residuals correlated }\end{array}$ & 28.37 & 6 & 0.001 & 4.73 & 0.947 & 0.095 & 0.021 & 0.474 \\
\hline
\end{tabular}

Note PFU = problematic Facebook use PVG = problematic video gaming. The selected model is marked in bold .

iors. Detailed findings are shown in Figure 1 and the Supplementary Materials.

For male gamers, the dimensions of self-control such as goal maintenance $(\beta=-0.14 ; p=.027)$ and inhibition and adjournment $(\beta=$ $-0.20, p<.001)$ were negatively and significantly associated with PFU. Also, there was positive relationship between PVG and weekly number of Facebook use hours $(\beta=0.25, p<.001)$. Additionally, the weekly number of Facebook use hours was positively associated with switching and flexibility $(\beta=0.13, p=.006)$ and negatively associated with age $(\beta=-0.10, p=.002)$. There was a negative relationship between PVG and self-control dimensions including initiative and persistence $(\beta=-0.14, p=.007)$ and inhibition and adjournment $(\beta=-0.21, p<$ $.001)$. Additionally, the weekly number of gaming hours was negatively associated with proactive control $(\beta=-0.10, p=.040)$ and age $(\beta=$ $-0.08, p=.044)$. There was also a positive relationship between the weekly number of gaming hours and PVG. Other paths were not statistically significant. Additionally, results also demonstrated a significant correlation between residuals of weekly gaming hours and Facebook hours $(r=0.24 ; p<.001)$, and between residuals of both problematic behaviors $(r=0.16 ; p=.005)$. Detailed findings are shown in Figure 2 and the Supplementary Materials.

The difference analysis results using the Wald test showed regression weights differences between male and female gamers in case of the relationship between PVG and inhibition and adjournment, $\chi^{2}(d f=1)$ $=10.28 ; p=.001$. The standardized regression weight was significant among male gamers $(\beta=-0.21, p<.001)$, whereas this path was not statistically significant among female gamers $(\beta=0.05, p=.478)$. In the case of the relationship between PFU and age, a significant difference between the groups was found, $\chi^{2}(d f=1)=5.02 ; p=.025$. The stand- ardized regression weight was significant $(\beta=0.11, p=.019)$ among female gamers but not among male gamers $(\beta=-0.04, p=.390)$.

Additionally, there was a significant difference between the groups in the relationship between the weekly number of Facebook hours and PFU, $\chi^{2}(d f=1)=14.54 ; p<.001$. The standardized regression weight was higher for female gamers $(\beta=0.49, p<.001)$ than for male gamers $(\beta=0.25, p<.001)$. In the case of the relationship between weekly Facebook use hours and switching and flexibility, significant differences between the groups were found, $\chi^{2}(d f=1)=4.59 ; p=.032$. The standardized regression weight was significant among male gamers $(\beta$ $=0.13, p=.006)$ but not among female gamers $(\beta=-0.02, p=.751)$. The other differences between female and male gamers in terms of analyzed paths (see Figures 1 and 2) were not statistically significant.

Based on the mediation analyses framework (Zhao et al., 2010; Mehmetoglu, 2018), significant mediation effects of PFU and PVG were found. More specifically, goal maintenance exerted a significant indirect effect on weekly Facebook use hours via PFU among both groups. Analogously, there was a significant indirect effect between initiative and persistence and weekly number of game hours via PVG among both groups. Taking into account the statistically nonsignificant direct effects between the weekly number of game hours and initiative and persistence, the results may indicate an indirect-only mediation (full mediation; see Zhao et al., 2010). Additionally, the findings showed a statistically significant indirect effect between inhibition and adjournment and weekly Facebook use hours via PFU in both groups. However, there was a significant direct effect between this selfcontrol dimension and number of weekly Facebook use hours among female gamers, whereas this direct effect was not statistically significant among male gamers. Consequently, these results may indicate a com- 


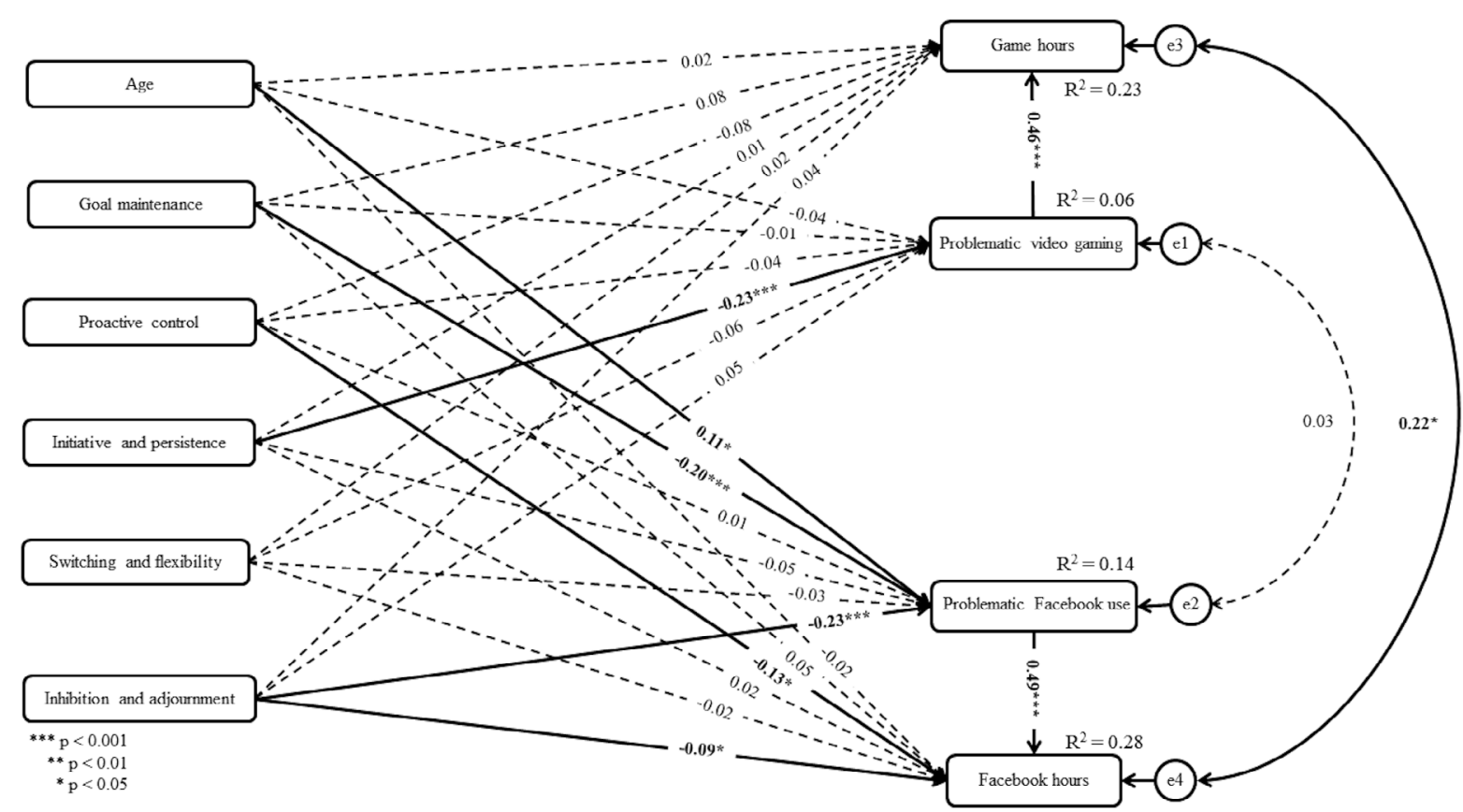

FIGURE 1.

The chosen model for female gamers.

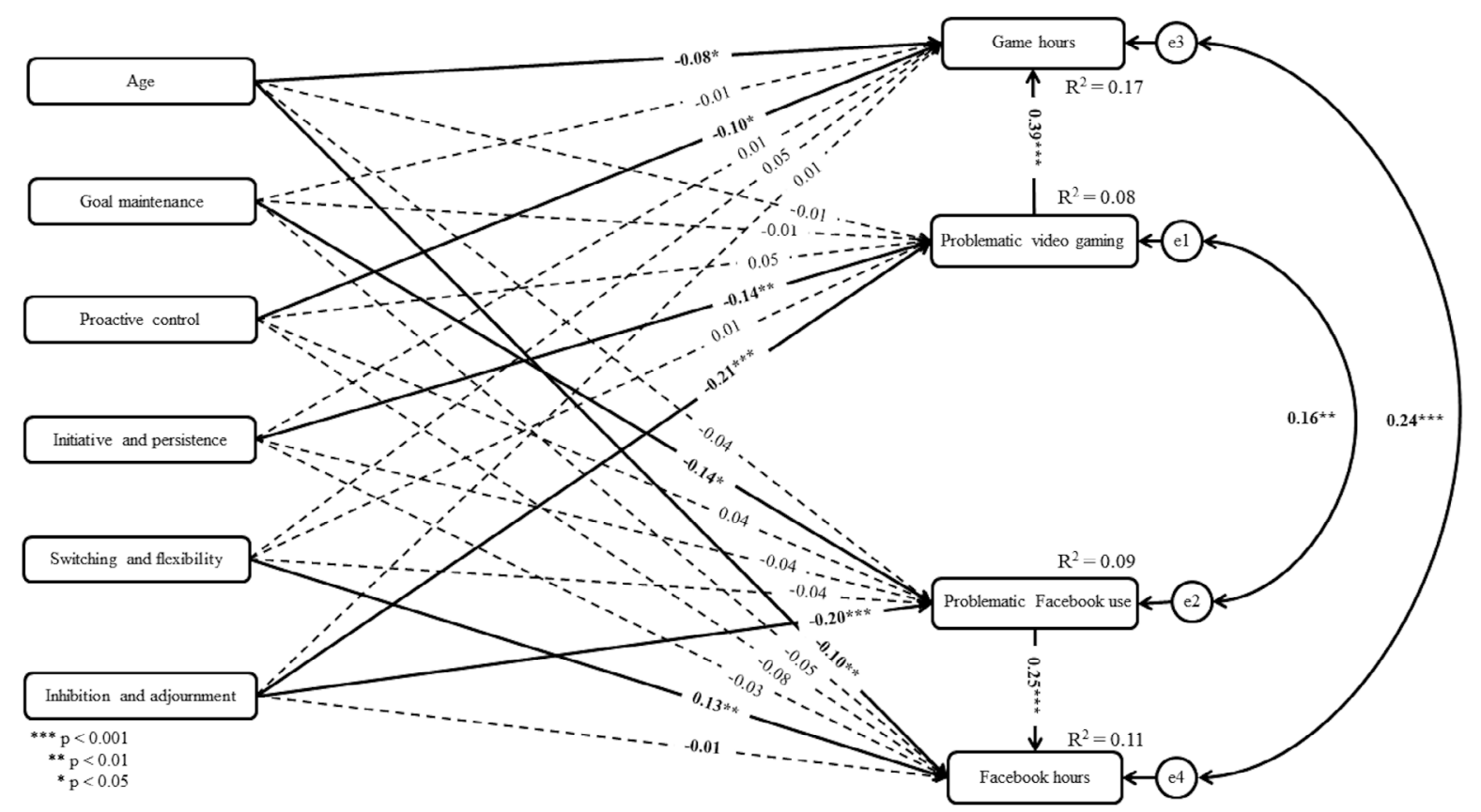

FIGURE 2.

The chosen model for male gamers. 


\begin{tabular}{|c|c|c|c|c|c|c|}
\hline \multicolumn{7}{|c|}{ Female gamers $(n=350)$} \\
\hline \multirow{2}{*}{ Model pathways } & \multirow{2}{*}{$\begin{array}{c}\text { Point } \\
\text { estimates }\end{array}$} & \multirow{2}{*}{$\mathrm{SE}$} & \multicolumn{2}{|c|}{$95 \% \mathrm{CI}$} & & \multirow{2}{*}{$p$} \\
\hline & & & Lower & Upper & & \\
\hline Goal maintenance $\rightarrow$ PFU $\rightarrow$ Facebook hours & -0.096 & 0.029 & -0.154 & -0.043 & -3.34 & .001 \\
\hline Inhibition and adjournment $\rightarrow \mathrm{PFU} \rightarrow$ Facebook hours & -0.111 & 0.028 & -0.168 & -0.060 & -4.00 & .001 \\
\hline Age $\rightarrow$ PFU $\rightarrow$ Facebook hours & 0.055 & 0.024 & 0.009 & 0.104 & 2.27 & .023 \\
\hline Initiative and persistence $\rightarrow$ PVG $\rightarrow$ game hours & -0.108 & 0.029 & -0.169 & -0.054 & -3.67 & .001 \\
\hline Inhibition and adjournment $\rightarrow$ PVG $\rightarrow$ game hours & 0.020 & 0.030 & -0.036 & 0.078 & 0.69 & 493 \\
\hline \multicolumn{7}{|c|}{ Male gamers $(n=480)$} \\
\hline Goal maintenance $\rightarrow$ PFU $\rightarrow$ Facebook hours & -0.035 & 0.017 & -0.072 & -0.005 & -2.06 & .040 \\
\hline Inhibition and adjournment $\rightarrow$ PFU $\rightarrow$ Facebook hours & -0.050 & 0.015 & -0.081 & -0.023 & -3.33 & .001 \\
\hline Age $\rightarrow$ PFU $\rightarrow$ Facebook hours & -0.011 & 0.013 & -0.038 & 0.014 & -0.86 & .392 \\
\hline Initiative and persistence $\rightarrow$ PVG $\rightarrow$ game hours & -0.059 & 0.023 & -0.105 & -0.016 & -2.58 & .010 \\
\hline Inhibition and adjournment $\rightarrow$ PVG $\rightarrow$ game hours & -0.083 & 0.021 & -0.125 & -0.045 & -4.02 & .001 \\
\hline
\end{tabular}

Note PFU = problematic Facebook use; $\mathrm{PVG}=$ problematic video gaming .

plementary mediation (partial mediation; see Zhao et al., 2010) among female gamers and an indirect-only mediation (full mediation; see Zhao et al., 2010) among male gamers. Additionally, there was a statistically significant indirect-only effect between age and weekly number of Facebook use hours via PFU (full mediation) among female gamers only. Inhibition and adjournment exerted a significant indirect-only effect on number of game hours via PVG (full mediation) among male gamers only. Detailed results are shown in Table 4.

\section{DISCUSSION}

The present study was conducted to investigate the relationship between PFU, PVG, and self-control dimensions among female and male gamers. The findings showed that lower goal maintenance was only associated with higher PFU, whereas lower initiative and persistence was associated only with higher PVG among both female and male gamers. Additionally, there was a negative relationship between inhibition and adjournment and PFU and PVG among male gamers. In contrast, among female gamers, PFU was only associated with inhibition and adjournment. In both the female and male groups, there was no relationship between the two problematic behaviors and the self-control dimension associated with switching and flexibility. Also, no relationship was found between problematic behaviors and proactive control among both female and male gamers. The findings showed the difference between both groups in the relationship between PVG and the self-control dimension associated with inhibition and adjournment. Additional differences between female and male gamers were also observed in the relationship between the other variables.

As hypothesized, lower goal maintenance was associated with higher problematic behaviors (H1). However, this relationship was only significant in the case of PFU among female and male gamers. This finding may indicate that lower ability among individuals to keep their own intentions and long-term plans in mind and to monitor the salience of important goals (see Nęcka et al., 2016, 2019) may contribute to increased problems with Facebook use. One possible explanation may be related to procrastination, characterized as "self-regulatory failure of not exerting self-control necessary for task engagement" (Sirois \& Pychyl, 2013, p. 116). In this context, it should be noted that procrastinating media use, characterized as irrational and dysfunctional delay of non-media activities (Klingsieck, 2013) may be driven by automatic media selection, which is facilitated by strong media habits and low motivation for behavioral control (Schnauber-Stockmann et al., 2018). Additionally, Meier et al. (2016) noted an association between habit strength and procrastinating Facebook use. In this context, Du et al. (2019) also showed that social media self-control failure is associated with the tendency to think frequently and intensively about online activities. Consequently, it can be assumed that an individual having difficulties with maintaining their higher-order goals is probably more likely to give up on their current activity in favor of using Facebook. Additionally, this may lead to an easier transition from functional to problematic Facebook use.

Additionally, the findings showed a negative relationship between inhibition and adjournment and PFU in both groups. Additionally, among male gamers only, PVG was associated with this self-control dimension. Consequently, these results partially support H2. Low inhibition and adjournment may be associated with low suppressed or delayed unwanted or improper actions that may contribute to the failure of goal-directed behavior. Additionally, it may also be associated with low ability to inhibit emotional reactions and refrain from immediate, impulsive behaviors (Nęcka et al., 2016, 2019). These results are in line with previous studies indicating the relationship between impulsivity and PFU (Sindermann et al., 2020; Cudo et al., 2020a; Turel et al., 2014; Turel \& Qahri-Saremi, 2016). The results obtained may be associated with the specifics of Facebook use. More specifically, 98\% of users access Facebook via smartphones (Statista, 2020), which is associated with receiving various types of notifications from the Facebook app. This notification is usually related to smartphone sounds, vibrations, and icon change. Consequently, the situation of receiving a notification signaled by sound or vibration is a potential D-G conflict (see Kotabe \& Hofmann, 2015) between checking the notification and continuing 
the current activity. In this context, low inhibition and adjournment may be conducive to interrupting the current activity and checking the notification (in particular, when the notification and related information is a form of gratification for the user; see Du et al., 2019; Griffiths, 2018a). Considering the relationship between media and selfcontrol described by Hofmann et al. (2017) and SCT theory (Kotabe \& Hofmann, 2015), unpredictable and immediate gratification associated with smartphone sounds and vibrations may be a major challenge for self-control which may provide self-control failure in relation to Facebook use (especially when there are additional difficulties with individual ability to keep own intentions and long-term plans in mind, i.e., low goal maintenance). In such a situation, interrupting the current activity may more easily lead to the start of accessing the Facebook app despite having other goals and plans. In the long term, this may lead to automatic and habitual activity associated with checking Facebook (see Du et al., 2019). Taken together, this may be one of the possible explanations of the mechanism associated with the relationship between dysfunctional self-control and PFU.

Only among male gamers was there was a negative relationship between PVG and inhibition and adjournment. As in the case of PFU, this may indicate that individuals who have difficulties with suppressed or delayed unwanted or improper actions (see Nęcka et al., 2016) may have a higher level of PVG. One possible explanation of this result may be related to the growing number of action games available for smartphones. Considering the high interest in action games among male gamers (ESA, 2019; PGO, 2019), this could lead to their use via smartphones. In this context, despite the main use of consoles (73\%) and computers $(67 \%)$ by Polish male gamers, the number of gamers playing via smartphones has increased from $44 \%$ in 2018 to $51 \%$ in 2019 (PGO, 2019). Consequently, notifications related to mobile games may probably have a similar consequence as Facebook notifications. More specifically, individuals with low inhibition and adjournment may have difficulty holding back from using the smartphone for gaming or maintaining their current activity when they receive a game notification (e.g., sound, vibration, etc.). These difficulties can also be reinforced by the possible gratification associated with the game itself (see King et al., 2010a). These assumptions may be supported by research indicating that only cognitive impulsivity (characterized as difficulties in staying focused on a task) was positively associated with PVG (Nuyens et al., 2016).

However, it should be noted that there was a significant difference between gender in the relationship between PVG and inhibition and adjournment (see H6). More specifically, this relationship was significant among male gamers only. One possible explanation for these differences may be related to the strength of the gratification associated with gaming. In this context, Lopez-Fernandez et al. (2019) noted that female gamers look for different things in videogames than male gamers, which are not often included in game designs, thereby limiting female gamers' abilities. Additionally, female gamers face the sexual (mis)representation of female characters in the game, online harassment, and the expectation that they are less skilfull players compared to male gamers (McLean \& Griffiths, 2019). In contrast, male gamers feel success and achievement when their playing time increases (Hamlen, 2010). Additionally, male gamers are driven by the desire to obtain in-game rewards and the desire to manipulate and learn about the game world and elements, whereas female players are more likely to be driven by the desire to initiate and maintain social contacts (King et al., 2010b). Similarity, Hoeft et al. (2008) postulated that videogames are more rewarding for male gamers than female gamers. Taken together, it can be assumed that male gamers with low inhibition and adjournment may have more difficulty in blocking the game behavior associated with a large gratification then female games, for whom the game is less rewarding. Consequently, low inhibition and adjournment may be a stronger PVG risk factor for male than female gamers.

The results also showed that lower initiative and persistence was associated with PVG among both female and male gamers, which partially supported H3. This finding may indicate that lower ability of efficient motivation induction and persistence in achieving a higher-order goal (see Nęcka et al., 2016, 2019) may contribute to increased problems with video gaming, irrespective of gender. Taking into account that control motivation is the aspiration to control desire (Kotabe \& Hofmann, 2015), lower initiative and persistence may also be associated with a lack of aspiration to control the temptation to game despite other important goals. In this context, previous research (Blasi et al., 2019; Király et al., 2015; Kuss et al., 2012) has shown a positive relationship between PVG and escapism (referring to the engagement in videogames to relax or to divert attention from real-life problems, Yee, 2006). Similarly, Mills and Allen (2020) showed that PVG is associated with amotivation, characterized as engaging in gaming despite the lack of volition to do so, and introjected regulation, which is associated with internal pressures (e.g., guilt, shame, obligation) to engage in videogame playing. Consequently, this finding may indicate that individuals with low initiative and persistence may have low motivation to resist the temptation to game, which can be a coping strategy to deal with negative situations in real life. Additionally, it can be presumed that individuals in hard life situations may want to play videogames as a way of coping, which may lead to difficulties in focusing on current goal-directed behavior. These assumptions are supported by research indicating that PVG may be associated with procrastination (Yeh et al., 2017). In this context, it should be noted that procrastinating media use (characterized as irrational and dysfunctional delay of non-media activities; Klingsieck, 2013) may be driven by automatic media selection, which is facilitated by strong media habits and low motivation for behavioral control (Schnauber-Stockmann et al., 2018). Additionally, procrastinators are aware of the negative effects of postponing behavior and want to limit this unwanted behavior (O'Brien, 2002). However, they are not able to resist temptation and despite struggling with temptation, ultimately they give in to it.

It should be noted that initiative and persistence had no relationship with PFU. This may be associated with the specifics of using videogames and Facebook. More specifically, considering the theoretically longer delay between the game temptation and the beginning of gaming, the dysfunction of initiative and persistence (low ability of efficient motivation induction to cope with the temptation to game in the 
delay) may be important alongside the dysfunction of inhibition and adjournment (low ability to inhibit immediately game-related activity) in developing problematic behavior. In contrast to gaming, taking into account that most individuals use Facebook on their smartphone and users can theoretically check posts and messages at any time, it is assumed that the delay between Facebook temptation and use is very short. Consequently, taking into account this very short delay, it can be cautiously assumed that low inhibition and adjournment may be more important than low initiative and persistence in developing a PFU.

As hypothesized, there was no relationship between problematic behaviors and self-control dimension associated with switching and flexibility (H4). These findings may indicate that the ability to switch between tasks and actions in order to avoid perseverance or learned irrelevance is not a significant predictor of PFU or PVG among female and male gamers. These assumptions are in line with previous studies indicating no relationship between media multitasking and PFU (Błachnio \& Przepiorka, 2016; Wang et al. , 2019) or PVG (Wang et al., 2019). However, the self-control dimension associated with switching and flexibility was associated with the weekly amount of time spent using Facebook among male gamers. Additionally, higher switching and flexibility was associated with more weekly hours spent using Facebook. One possible explanation for this may be related to media multitasking, which is associated with the ability to engage in multiple media use simultaneously or a tendency to switch between different media (Ophir et al., 2009). More specifically, individuals with higher switching and flexibility may be able to switch more easily between gaming and using Facebook. Consequently, taking into account that male gamers (compared to female gamers) spend more time gaming (see Table 2) and more often play action games (ESA, 2019; Lopez-Fernandez et al., 2019), which are very engaging (Boyle et al., 2012; Dickey, 2005), they do not have to stop using Facebook for the duration of the game, because they are able to use both media at once. Additionally, it should be noted that female gamers aged 18 to 34 years most often play games on their smartphone whereas male gamers in this age range most often play games on their game console (ESA, 2019). Consequently, it is assumed that male gamers have to use two devices (e.g., a console and a smartphone) more often in order to engage in gaming and Facebook use simultaneously. Consequently, high switching and flexibility may be conducive to more time being spent on Facebook among male gamers. These assumptions support the findings of the present study, which indicated a significant difference between the female and male gamers in their relationship between time spent using Facebook and switching and flexibility.

Additionally, the findings showed no relationship between problematic behaviors and proactive control, which confirms H5. These results may indicate that low ability to undertake necessary arrangements and foresee possible obstacles in goal-directed behaviors (see Nęcka et al., 2016) is probably not associated with problematic behaviors. However, the findings showed a negative relationship between proactive control and weekly hours spent using Facebook among female gamers. Additionally, there was a negative relationship between proactive control and weekly gaming time among male gamers. These results indicate that low proactive control is associated with longer media use time without causing problematic behaviors. It should be noted the difference between female and male gamers may also be associated with media preference. On the one hand, females spend more time using Facebook than male users (see Table 2), and the relationship between weekly number of Facebook hours and PFU is stronger for females compared to males. On the other hand, female gamers spend less time gaming and have less PVG then male gamers (see Table 2). In this context, Chan et al. (2015) reported that entertainment has a more important role in determining Facebook satisfaction for males, whereas relationship maintenance is more important in determining Facebook satisfaction for female users. Additionally, Chou and Tsai (2007) showed that male gamers have a stronger motivation for gaming than females, which was associated with entertainment, seeking information, and social device. Also, among male gamers, the increased playing time may lead to increased feelings of success and achievement, which then leads to increased playing time (Hamlen, 2010). In contrast, McLean and Griffiths (2019) reported that female gamers played alone, played anonymously, and changed groups regularly because they often experienced a lack of support and harassment when gaming online alongside males. Taken together, female and male gamers may experience different preferences for the gratification they receive when gaming and using Facebook. Consequently, they are likely to use the medium that gives them the most gratification. However, they may use videogames or Facebook more than they intended when they have low ability to create plans, prioritize goals, analyze consequences, and predict obstacles (Nęcka et al., 2016, 2019).

Additionally, the findings showed a negative relationship between weekly Facebook use hours and age as well as between game hours and age among male gamers. This may indicate that male gamers spend less and less time playing games and using Facebook as they get older. In this context, Ream et al. (2013) found that the number of gaming days and PVG had curvilinear relationships with age. More specifically, they increased through childhood and adolescence to a peak and then leveled off or decreased in emerging adulthood. Consequently, considering that males spend more hours playing videogames than female gamers, additional responsibilities related to studying and paid work may contribute to reducing the number of hours spent playing games. Additionally, it can be assumed that this also contributes to reduction of time spent on Facebook among male gamers. It should be noted that there was a significant difference between both groups in case of a relationship between age and PFU. More specifically, the relationship was positive and significant among female gamers, whereas it was nonsignificant among male gamers. In this context, Facebook is a more important medium for females in terms of social relationships and creating their image than for males (Haferkamp et al., 2012; Thompson \& Lougheed, 2012; Tifferet \& Vilnai-Yavetz, 2014). Consequently, taking into account that in the current study, the female participants were aged between 16 and 31 years, which is a time of changes in social and professional life (Schwartz \& Petrova, 2019), PFU may be a coping strategy. However, considering that the magnitude of the relationship was low, this assumption should be approached with caution. 
Additionally, the results showed that female gamers had higher levels of PFU than male gamers. In contrast, males had higher levels of PVG then female gamers (see Table 2). These findings are in line with previous findings (Andreassen et al., 2016; Atroszko et al., 2018; Błachnio, Przepiorka, \& Pantic, 2016; Cudo et al., 2020b; Griffiths et al., 2016). Moreover, the results showed that only one model out of eight was well fit to the data (see Table 3). It was a model assuming the relationship between PFU residual and PVG residual as well as between Facebook hours residual and videogame playing hours residual. This model also assumed that weekly Facebook hours and videogame playing hours are consequences of PFU and PVG, respectively. In this context, some previous studies (Brailovskaia et al., 2018; Cudo, Kopiś, Zabielska-Mendyk, 2019; Kuss et al., 2012) viewed the time spent on Facebook or videogames as predictors of problematic behavior. However, other research (Triberti et al., 2018; Turel, 2015; Turel et al., 2018) viewed the time spent on Facebook or videogames as the consequences of problematic behavior. However, it should be noted that according to the I-PACE model, Brand et al. (2016) postulated a shift from gratification to compensation during the addiction process. More specifically, in the beginning, participants may experience the gratification associated with the use of the medium such as Facebook or a videogame, so they may spend more and more time using it. However, when the gratification switches to compensation, the use of the medium will be more the result of problematic behavior. Therefore, different results of previous survey research, in which regression methods were used, may be related to this type of mechanism described in the I-PACE model. However, further research is needed to verify this assumption.

In conclusion, the findings showed that the problematic behaviors (PFU and PVG) were negatively related to specific dimensions of self-control (i.e., goal maintenance, inhibition and adjournment, initiative, and persistence), but there was no relationship with other dimensions of self-control (i.e., proactive control, switching and flexibility). Additionally, the negative relationships between dimensions of self-control and these problematic behaviors were different for male and female gamers. These differences may be related to the fact that videogames are more rewarding for male gamers than female gamers (Hoeft et al., 2008). Additionally, the findings showed that dimensions of self-control were also associated with time spent on Facebook and gaming. Consequently, these results may indicate that problematic behaviors are only associated with specific deficits in self-control dimensions associated with deficit in direct goal maintenance, lack of efficient motivation induction, lack of persistence in achieving higher-order goals, and deficit in suppressed and delayed unwanted actions.

\section{Limitations and Future Studies}

The results presented in this study should be interpreted in light of several limitations. The participants were all young Polish gamers, so the results are not representative of non-gamer groups and should be treated cautiously when referring to other cultures. More specifically, gender roles in European countries such as Poland could be different from Asian countries, which may further influence the gender differences in problematic behaviors (Su et al., 2019). Methodologically, the study utilized self-report methods and was cross-sectional. Consequently, there are well-known method biases when participants answer such questions (e.g., social desirability), and only longitudinal studies can provide insights into the causality of the significant associations found among the variables of interest. Additionally, further research needs to establish whether similar relationships between PVG and self-control dimensions can be identified in other gamer groups such as children, adolescents, or seniors. Problematic Facebook use is only one example of problematic SNS use (Kuss \& Griffiths, 2017). Therefore, it is important to be careful in generalizing the results to other SNS platforms. Additionally, Facebook use does not comprise a single type of activity and users can play games, gamble online, watch videos, share photos, update their profiles, and message their friends (Griffiths, 2012; Kuss \& Griffiths, 2017). Consequently, this specificity of Facebook should be taken into account when trying to compare results to other SNS platforms. Moreover, the specific types of games the participants were playing and their gaming behavior on Facebook was not assessed. Consequently, care should be taken when interpreting results of present study for gamers playing different types of games. Finally, the present study focused on analyzing the relationship between selfcontrol dimensions and problematic behavior. Taking into account the relationship between self-control and wellbeing (De Ridder et al., 2012), and problematic behavior and health problems (Brailovskaia et al., 2019a; Burleigh et al., 2019), further studies should consider the relationship between health, self-control, and problematic behavior.

\section{ACKNOWLEDGEMENTS}

This study was partly based on research project funded by the Gambling Problem Solving Fund (Polish: Fundusz Rozwiązywania Problemów Hazardowych), administered by the Minister of Health (No. 190/HM/2017).

Authors' contribution. AC: substantial contributions to the conception and design of the work and. AC and TM: the data acquisition; $A C$ : the data analysis; $A C, T M$ and $M T$, interpretation of data for the work. AC, TM and MDG: drafting the work. AC, TM, MDG, and MT: revising the work critically for important intellectual content.

Conflict of interest. The authors declare no conflict of interest.

\section{REFERENCES}

Acock, A. C. (2013). Discovering structural equation modeling using Stata: Revised edition. College Station: Stata Press Books.

American Psychiatric Association (2013). Diagnostic and statistical manual of mental disorders (5th ed.). American Psychiatric Association.

Andreassen, C. S., Torsheim, T., Brunborg, G. S., \& Pallesen, S. (2012). Development of a Facebook addiction scale. Psychological Reports,

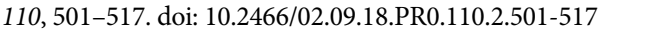

Andreassen, S. C., \& Pallesen, S. (2014). Social network site addictionan overview. Current Pharmaceutical Design, 20, 4053-4061. سلس الس 
Andreassen, C. S., Billieux, J., Griffiths, M. D., Kuss, D. J., Demetrovics, Z., Mazzoni, E., \& Pallesen, S. (2016). The relationship between addictive use of social media and video games and symptoms of psychiatric disorders: A large-scale cross-sectional study. Psychology of Addictive Behaviors, 30, 252-262.

Atroszko, P. A., Balcerowska, J. M., Bereznowski, P., Biernatowska, A., Pallesen, S., \& Andreassen, C. S. (2018). Facebook addiction among Polish undergraduate students: Validity of measurement and relationship with personality and well-being. Computers in Human Behavior, 85, 329-338. doi: 10.1016/j.chb.2018.04.001 السلسلسلة

Bailey, K., West, R., \& Kuffel, J. (2013). What would my avatar do? Gaming, pathology, and risky decision making. Frontiers in Psychology, 4, 609. doi: 10.3389/fpsyg.2013.00609 السلسلسلة

Billieux, J., Deleuze, J., Griffiths, M. D., \& Kuss, D. J. (2015). Internet gaming addiction: The case of massively multiplayer online roleplaying games. In: N. el-Guebaly et al. (eds.). Textbook of addiction treatment: International perspectives (pp. 1515-1525). SpringerVerlag.

Blasi, M. D., Giardina, A., Giordano, C., Coco, G. L., Tosto, C., Billieux, J., \& Schimmenti, A. (2019). Problematic video game use as an emotional coping strategy: Evidence from a sample of MMORPG gamers. Journal of Behavioral Addictions, 8, 25-34. doi: 10.1556/2006.8.2019.02 الم

Blinka, L., Škařupová, K., \& Mitterova, K. (2016). Dysfunctional impulsivity in online gaming addiction and engagement. Cyberpsychology: Journal of Psychosocial Research on Cyberspace, 10, 5. doi: 10.5817/ CP2016-3-5 الملسلسلة

Błachnio, A., \& Przepiorka, A. (2016). Dysfunction of self-regulation and self-control in Facebook addiction. Psychiatric Quarterly, 87, 493-500. doi: 10.1007/s11126-015-9403-1. doi: 10.1007/s11126-

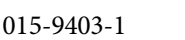

Błachnio, A., Przepiorka, A., \& Pantic, I. (2016). Association between Facebook addiction, self-esteem and life satisfaction: A crosssectional study. Computers in Human Behavior, 55, 701-705. doi: 10.1016/j.chb.2015.10.026 الملسلس

Błachnio, A., Przepiorka, A., Bałakier, E., \& Boruch, W. (2016a). Who discloses the most on Facebook? Computers in Human Behavior, 55, 664-667. doi: 10.1016/j.chb.2015.10.007 السلسلس

Błachnio, A., Przepiorka, A., Benvenuti, M., Cannata, D., Ciobanu, A. M., Senol-Durak, E., ... \& Popa, C. (2016b). An international perspective on Facebook intrusion. Psychiatry Research, 242, 385-387. doi: 10.1016/j.psychres.2016.06.015 السلسلس

Błachnio, A., \& Przepiorka, A. (2018). Facebook intrusion, fear of missing out, narcissism, and life satisfaction: A cross-sectional study. Psychiatry Research, 259, 514-519. doi: 10.1016/j.psychres.2017.11.012 السلسلس

Botella, C., Riva, G., Gaggioli, A., Wiederhold, B. K., Alcaniz, M., \& Banos, R. M. (2012). The present and future of positive technologies. Cyberpsychology, Behavior, and Social Networking, 15, 78-84. doi: 10.1089/cyber.2011.0140 سلس سلس

Boyle, E. A., Connolly, T. M., Hainey, T., \& Boyle, J. M. (2012). Engagement in digital entertainment games: A systematic re- view. Computers in Human Behavior, 28, 771-780. doi: 10.1016/j. chb.2011.11.020 |سلس |لس

Brailovskaia, J., \& Margraf, J. (2017). Facebook Addiction Disorder (FAD) among German students - A longitudinal approach. Plos One, 12, e0189719. doi: 10.1371/journal.pone.0189719 الم

Brailovskaia, J., Schillack, H., \& Margraf, J. (2018). Facebook Addiction Disorder in Germany. Cyberpsychology, Behavior, and Social Networking, 21, 450-456. doi: 10.1089/cyber.2018.0140 سلس

Brailovskaia, J., Velten, J., \& Margaf, J. (2019a). Relationship between daily stress, depression symptoms, and Facebook addiction disorder in Germany and in the United States. Cyberpsychology, Behavior, and Social Networking, 22, 610-614. doi: 10.1089/cyber.2019.0165 الس الس Brailovskaia, J., Rohmann, E., Bierhoff, H.-W., Margraf, J., \& Köllner, V. (2019b). Relationships between addictive Facebook use, depressiveness, insomnia, and positive mental health in an inpatient sample: A German longitudinal study. Journal of Behavioral Addictions, 8, 703-713. doi: 10.1556/2006.8.2019.63 السلسلس

Brailovskaia, J., Teismann, T., \& Margraf, J. (2020). Positive mental health mediates the relationship between Facebook Addiction Disorder and suicide-related outcomes: A longitudinal approach. Cyberpsychology, Behavior, and Social Networking, 23, 346-350. doi: 10.1089/cyber.2019.0563 友

Brand, M., Young, K. S., Laier, C., Wölfling, K., \& Potenza, M. N. (2016). Integrating psychological and neurobiological considerations regarding the development and maintenance of specific Internet-use disorders: An Interaction of Person-Affect-Cognition-Execution (I-PACE) model. Neuroscience and Biobehavioral Reviews, 71, 252-266. doi: 10.1016/j.neubiorev.2016.08.033 السلسلسلس

Brand, M., Wegmann, E., Stark, R., Müller, A., Wölfling, K., Robbins, T. W., \& Potenza, M. N. (2019). The Interaction of Person-AffectCognition-Execution (I-PACE) model for addictive behaviors: Update, generalization to addictive behaviors beyond internet-use disorders, and specification of the process character of addictive behaviors. Neuroscience and Biobehavioral Reviews, 104, 1-10. doi: 10.1016/j.neubiorev.2019.06.032 السلسلس الس

Burleigh, T. L., Griffiths, M. D., Sumich, A., Stavropoulos, V., \& Kuss, D. J. (2019). A systematic review of the co-occurrence of Gaming Disorder and other potentially addictive behaviors. Current Addiction Reports, 6, 383-401. doi: 10.1007/s40429-019-00279-7 المالسلسلة

Carver, C. S. (2005). Impulse and constraint: Perspectives from personality psychology, convergence with theory in other areas, and potential for integration. Personality and Social Psychology Review,

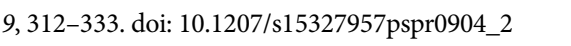

Chan, T. K., Cheung, C. M., Shi, N., \& Lee, M. K. (2015). Gender differences in satisfaction with Facebook users. Industrial Management and Data Systems, 115, 82-206. doi: 10.1108/IMDS-08-2014-0234 الملالسلس

Chen, Z., Liu, P., Zhang, C., \& Feng, T. (2019). Brain morphological dynamics of procrastination: The crucial role of the self-control, emotional, and episodic prospection network. Cerebral Cortex, 30, 2834-2853. doi: 10.1093/cercor/bhz278 السلسلسلس

Chou, C., \& Tsai, M. J. (2007). Gender differences in Taiwan high school students' computer game playing. Computers in Human 
Behavior, 23, 812-824. doi: 10.1016/j.chb.2004.11.011 سلس

Columb, D., Griffiths, M. D., \& O'Gara, C. (2019). Online gaming and gaming disorder: More than just a trivial pursuit. Irish Journal of Psychological Medicine. Epub ahead of print. doi: 10.1017/ ipm.2019.31 سلس

Cudo, A., Kopiś, N., Stróżak, P., \& Zapała, D. (2018). Problematic video gaming and problematic internet use among Polish young adults. Cyberpsychology, Behavior, and Social Networking, 21, 523-529. doi: 10.1089/cyber.2018.0014 سلس

Cudo, A., Kopiś, N., \& Zabielska-Mendyk, E. (2019). Personal distress as a mediator between self-esteem, self-efficacy, loneliness and problematic video gaming in female and male emerging adult gamers. Plos One, 14, e0226213. doi: 10.1371/journal.pone.0226213 المالسلسا

Cudo, A., Kopiś, N., Francuz, P., Błachnio, A., Przepiórka, A., \& Torój, M. (2019). The impact of Facebook use and Facebook intrusion on cognitive control: Effect in proactive and reactive control. Advances

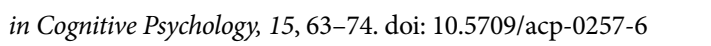

Cudo, A., Torój, M., Demczuk, M., \& Francuz, P. (2020a). Dysfunction of self-control in Facebook addiction: Impulsivity is the key. Psychiatric Quarterly, 91, 91-101. doi: 10.1007/s11126-019-09683-8 المالسلسل|

Cudo, A., Torój, M., Misiuro, T., Griffiths, M. D. (2020b). Problematic Facebook use and problematic video gaming among female and male gamers. Cyberpsychology, Behavior, and Social Networking, 23, 126-133. doi: 10.1089/cyber.2019.0252 السلسلس

De Ridder, D. T., Lensvelt-Mulders, G., Finkenauer, C., Stok, F. M., \& Baumeister, R. F. (2012). Taking stock of self-control: A meta-analysis of how trait self-control relates to a wide range of behaviors. Personality and Social Psychology Review, 16, 76-99. doi: 10.1177/1088868311418749 سلس

Deleuze, J., Nuyens, F., Rochat, L., Rothen, S., Maurage, P., \& Billieux, J. (2017). Established risk factors for addiction fail to discriminate between healthy gamers and gamers endorsing DSM-5 internet gaming disorder. Journal of Behavioral Addictions, 6, 516-524. doi: 10.1556/2006.6.2017.074 السلس

Dickey, M. D. (2005). Engaging by design: How engagement strategies in popular computer and video games can inform instructional design. Educational Technology Research and Development, 53, 67-83. doi: 10.1007/BF02504866 السلسلس

Drummond, A., \& Sauer, J. D. (2018). Video game loot boxes are psychologically akin to gambling. Nature Human Behavior, 2, 530-532. doi: 10.1038/s41562-018-0360-1 |سلس

Du, J., Kerkhof, P., \& van Koningsbruggen, G. M. (2019). Predictors of social media self-control failure: Immediate gratifications, habitual checking, ubiquity, and notifications. Cyberpsychology, Behavior, and Social Networking, 22, 477-485. doi: 10.1089/cyber.2018.0730 WШ

Elphinston, R. A., Noller, P. (2011). Time to face it! Facebook intrusion and the implications for romantic jealousy and relationship satisfaction. Cyberpsychology, Behavior, and Social Networking, 14, 631-635. doi: 10.1089/cyber.2010.0318 سلس سلس

Entertainment Software Association (2019). Essential facts about the computer and video game industry. Retrieved March 9, 2020, from: https://www.theesa.com/wp-content/uploads/2019/05/ ESA_Essential_facts_2019_final.pdf

Fritz, C. O., Morris, P. E., \& Richler, J. J. (2012). Effect size estimates: Current use, calculations, and interpretation. Journal of Experimental Psychology: General, 141, 2-18. doi: 10.1037/a0024338 السلسل

Gervasi, A. M., La Marca, L., Costanzo, A., Pace, U., Guglielmucci, F., \& Schimmenti, A. (2017). Personality and internet gaming disorder: A systematic review of recent literature. Current Addiction Reports, 4, 293-307. doi: 10.1007/s40429-017-0159-6 المالسلس

Griffiths, M. D. (1996). Behavioural addictions: An issue for everybody. Employee Counselling Today: Journal of Workplace Learning,

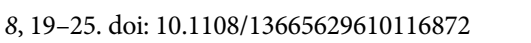

Griffiths, M. D. (2005). A “components" model of addiction within a biopsychosocial framework. Journal of Substance Use, 10, 191-197. doi: 10.1080/14659890500114359 الم

Griffiths, M. D. (2010). The role of context in online gaming excess and addiction: Some case study evidence. International Journal of Mental

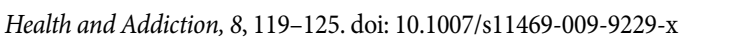
Griffiths, M. D. (2012). Facebook addiction: Concerns, criticisms and recommendations. Psychological Reports, 110, 518-520. doi: 10.2466/01.07.18.PR0.110.2.518-520 البسلسلس

Griffiths, M. D. (2018a). Adolescent social networking: How do social media operators facilitate habitual use? Education and Health, 36,

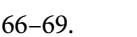

Griffiths, M. D. (2018b). Is the buying of loot boxes in video games a form of gambling or gaming? Gaming Law Review, 22, 52-54. doi: 10.1089/glr2.2018.2216 الملسلس

Griffiths, M. D. (2018c). Hot topics in gambling: Gambling blocking apps, loot boxes, and 'crypto-trading addiction'. Online Gambling Laer, 17, 9-11. سلس

Griffiths, M. D. (2019). The evolution of the 'components model of addiction' and the need for a confirmatory approach in conceptualizing behavioral addictions. Düşünen Adam The Journal of Psychiatry and Neurological Sciences, 32, 179-184. Wلس الس

Griffiths, M. D., Kuss, D. J., \& Pontes, H. M. (2016). A brief overview of Internet gaming disorder and its treatment. Australian Clinical Psychologist, 2, 20108. السلسلس

Griffiths, M. D., \& Nuyens, F. (2017). An overview of structural characteristics in problematic video game playing. Current Addiction Reports, 4, 272-283. المالسلسلة

Haferkamp, N., Eimler, S. C., Papadakis, A. M., \& Kruck, J. V. (2012). Men are from Mars, women are from Venus? Examining gender differences in self-presentation on social networking sites. Cyberpsychology, Behavior, and Social Networking, 15, 91-98. doi: 10.1089/cyber.2011.0151 Ш山س

Hamlen, K. R. (2010). Re-examining gender differences in video game play: Time spent and feelings of success. Journal of Educational Computing Research, 43, 293-308. doi: 10.2190/EC.43.3.b الملسلس

Hartmann, T., \& Klimmt, C. (2006). Gender and computer games: Exploring females' dislikes. Journal of ComputerMediated Communication, 11, 910-931. doi: 10.1111/j.10836101.2006.00301.x سلس 
Hoeft, F., Watson, C. L., Kesler, S. R., Bettinger, K. E., \& Reiss, A. L. (2008). Gender differences in the mesocorticolimbic system during computer game-play. Journal of Psychiatric Research, 42, 253-258. doi: 10.1016/j.jpsychires.2007.11.010 سلس

Hofmann, W., Friese, M., \& Strack, F. (2009). Impulse and self-control from a dual-systems perspective. Perspectives on Psychological Science, 4, 162-176. doi: 10.1111/j.1745-6924.2009.01116.x السلسلس

Hofmann, W., Vohs, K. D., \& Baumeister, R. F. (2012). What people desire, feel conflicted about, and try to resist in everyday life. Psychological Science, 23, 582-588. doi: 10.1177/0956797612437426 السلسلس

Hofmann, W., Reinecke, L., \& Meier, A. (2017). Of sweet temptations and bitter aftertaste: Self-control as a moderator of the effects of media use on well-being. In L. Reinecke \& M. B. Oliver (Eds.), The Routledge handbook of media use and well-being: International perspectives on theory and research on positive media effects (pp. 211-222). Routledge.

Hu, L. T., \& Bentler, P. M. (1999). Cutoff criteria for fit indexes in covariance structure analysis: Conventional criteria versus new alternatives. Structural Equation Modeling, 6, 1-55. doi: 10.1080/10705519909540118 السلسلس Eq

Khang, H., Kim, J. K., \& Kim, Y. (2013). Self-traits and motivations as antecedents of digital media flow and addiction: The Internet, mobile phones, and video games. Computers in Human Behavior, 29, 2416-2424. doi: 10.1016/j.chb.2013.05.027 المالسلسلة

Kim, S. K., Kim, S. Y., \& Kang, H. B. (2016). An analysis of the effects of smartphone push notifications on task performance with regard to smartphone overuse using ERP. Computational Intelligence and Neuroscience, 2016, 5718580. doi: 10.1155/2016/5718580 السلسلس

Kim, E. J., Namkoong, K., Ku, T., \& Kim, S. J. (2008). The relationship between online game addiction and aggression, self-control and narcissistic personality traits. European Psychiatry, 23, 212-218. doi: 10.1016/j.eurpsy.2007.10.010 سلس

King, D., Delfabbro, P., \& Griffiths, M. D. (2010a). Video game structural characteristics: A new psychological taxonomy. International Journal of Mental Health and Addiction, 8, 90-106. doi: 10.1007/ s11469-009-9206-4 لس

King, D., Delfabbro, P., \& Griffiths, M. D. (2010b). The role of structural characteristics in problem video game playing: A review. Cyberpsychology: Journal of Psychosocial Research on Cyberspace, 4, 6. 14.

King, D. L., Haagsma, M. C., Delfabbro, P. H., Gradisar, M., \& Griffiths, M. D. (2013). Toward a consensus definition of pathological video-gaming: A systematic review of psychometric assessment tools. Clinical Psychology Review, 33, 331-342. doi: 10.1016/j. cpr.2013.01.002 س山ा

Király, O., Urbán, R., Griffiths, M. D., Ágoston, C., Nagygyörgy, K., Kökönyei, G., \& Demetrovics, Z. (2015). The mediating effect of gaming motivation between psychiatric symptoms and problematic online gaming: An online survey. Journal of Medical Internet Research, 17, e88. doi: 10.2196/jmir.3515 اله السلس

Kline, R. B. (2011) Principles and practice of structural equation modeling. Guilford Press.
Klingsieck, K. B. (2013). Procrastination. When good things don't come to those who wait. European Psychologist,18, 24-34. doi:

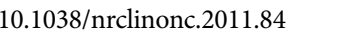

Kotabe, H. P., \& Hofmann, W. (2015). On integrating the components of self-control. Perspectives on Psychological Science, 10, 618-638. doi: 10.1177/1745691615593382 الس السلس

Kotabe, H. P., \& Hofmann, W. (2016). How depletion operates in an integrative theory of self-control. In Hirt, E. R., Clarkson, J. J., \& Jia, Lile (eds.), Self-regulation and ego control (pp. 399-423). Academic Press.

Kuhl J. (1994) Action versus state orientation: Psychometric properties of the Action Control Scale (ACS-90). In: J. Kuhl, \& J. Beckmann (Eds.). Volition and personality: Action versus state orientation (pp. 47-59). Hogrefe.

Kuss, D. J., \& Griffiths, M. D. (2012). Internet gaming addiction: A systematic review of empirical research. International Journal of Mental Health and Addiction, 10, 278-296. doi: 10.1007/s11469-011-9318-5 البلسلسلس

Kuss, D. J., \& Griffiths, M. D. (2017). Social networking sites and addiction: Ten lessons learned. International Journal of Environmental Research and Public Health, 14, 311. doi: 10.3390/ijerph14030311 المسلسلة Kuss, D. J., Louws, J., \& Wiers, R. W. (2012). Online gaming addiction? Motives predict addictive play behavior in massively multiplayer online role-playing games. Cyberpsychology, Behavior, and Social Networking, 15, 480-485. doi: 10.1089/cyber.2012.0034 السلسلس

Lee, C. D., \& Daiute, C. (2019). Introduction to developmental digital technologies in human history, culture, and well-being. Human Development, 62, 5-13. doi: 10.1159/000496072 السلسلس

Lindner, C., Nagy, G., \& Retelsdorf, J. (2015). The dimensionality of the Brief Self-Control Scale-An evaluation of unidimensional and multidimensional applications. Personality and Individual Differences, 86, 465-473. doi: 10.1016/j.paid.2015.07.006 السلسلس

Lopez-Fernandez, O., Williams, A. J., Griffiths, M. D., \& Kuss, D. J. (2019). Female gaming, gaming addiction, and the role of women within gaming culture: A narrative literature review. Frontiers in Psychiatry, 10, 454. doi: 10.3389/fpsyt.2019.00454 المالسلسلة

Lynam, D. R., Smith, G. T., Whiteside, S. P., \& Cyders, M. A. (2006). The UPPS-P: Assessing five personality pathways to impulsive behavior (Technical Report). Purdue University.

Maloney, P. W., Grawitch, M. J., \& Barber, L. K. (2012). The multi-factor structure of the Brief Self-Control Scale: Discriminant validity of restraint and impulsivity. Journal of Research in Personality, 46, 111-115. doi: 10.1016/j.jrp.2011.10.001 السلسالس

Mann, H. B., \& Whitney, D. R. (1947). On a test of whether one of two random variables is stochastically larger than the other. Annals of Mathematical Statistics, 18, 50-60. ШШШ

Marino, C., Gini, G., Vieno, A., \& Spada, M. M. (2018). A comprehensive meta-analysis on problematic Facebook use. Computers in Human Behavior, 83, 262-277. doi: 10.1016/j.chb.2018.02.009 الملسلسلة

McLean, L., \& Griffiths, M. D. (2019). Female gamers' experience of online harassment and social support in online gaming: A qualitative study. International Journal of Mental Health and Addiction, 17, 970-994. doi: 10.1007/s11469-018-9962-0 
Mehmetoglu, M. (2018). Medsem: A Stata package for statistical mediation analysis. International Journal of Computational Economics

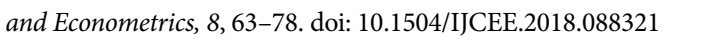

Mehroof, M., \& Griffiths, M. D. (2010). Online gaming addiction: The role of sensation seeking, self-control, neuroticism, aggression, state anxiety, and trait anxiety. Cyberpsychology, Behavior, and Social Networking, 13, 313-316. doi: 10.1089/cyber.2009.0229 السلسلس

Meier, A., Reinecke, L., \& Meltzer, C. E. (2016). "Facebocrastination"? Predictors of using Facebook for procrastination and its effects on students' well-being. Computers in Human Behavior, 64, 65-76. doi: 10.1016/j.chb.2016.06.011 البلسلسلة

Mills, D. J., \& Allen, J. J. (2020). Self-determination theory, internet gaming disorder, and the mediating role of self-control. Computers in

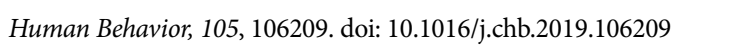

Mihara, S., \& Higuchi, S. (2017). Cross-sectional and longitudinal epidemiological studies of Internet gaming disorder: A systematic review of the literature. Psychiatry and Clinical Neurosciences, 71,

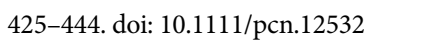

Muraven, M., \& Baumeister, R. F. (2000). Self-regulation and depletion of limited resources: Does self-control resemble a muscle? Psychological Bulletin, 126, 247-259. doi: 10.1037/0033-

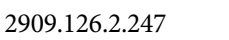

Nęcka, E. (2015). Self-control scale AS-36: Construction and validation study. Polish Psychological Bulletin, 46, 488-497. doi: 10.1515/ ppb-2015-0055 الملسلسلس

Nęcka, E., Wujcik, R., Orzechowski, J., Gruszka, A., Janik, B., \& Wójcik, N. (2016). NAS-50 and NAS-40: New scales for the assessment of self-control. Polish Psychological Bulletin, 47, 346-355. doi: 10.1515/

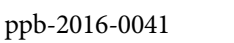

Nęcka, E., Korona-Golec, K., Hlawacz, T., Nowak, M., \& GruszkaGosiewska, A. (2019). The relationship between self-control and temperament: A contribution to self-control definition debate. Current Issues in Personality Psychology, 7, 24-31. doi: 10.5114/ cipp.2019.82922

Nuyens, F., Deleuze, J., Maurage, P., Griffiths, M. D., Kuss, D. J., \& Billieux, J. (2016). Impulsivity in multiplayer online battle arena gamers: Preliminary results on experimental and selfreport measures. Journal of Behavioral Addictions, 5, 351-356. doi: 10.1556/2006.5.2016.028

O'Brien, W. K. (2002). Applying the transtheoretical model to academic procrastination. Dissertation Abstracts International: Section

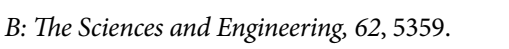

Ophir, E., Nass, C., \& Wagner, A. D. (2009). Cognitive control in media multitaskers. Proceedings of the National Academy of Sciences, 106, 15583-15587. doi: 10.1073/pnas.0903620106 سلس

Pew Research Center. (2019). Social media update 2019. Retrieved March 9, 2020, from: https://www.pewresearch.org/facttank/2019/04/10/share-of-u-s-adults-using-social-media-including-facebook-is-mostly-unchanged-since-2018/

Polish Gamers Observatory. (2019). Polish Gamers Research '19. Retrieved March 9, 2020, from: https://polishgamers.com/pgr/ polish-gamers-research-2019
Pontes, H. M. (2017). Investigating the differential effects of social networking site addiction and Internet gaming disorder on psychological health. Journal of Behavioral Addictions, 6, 601-610. doi: 10.1556/2006.6.2017.075 الس

Przepiorka, A., Błachnio, A., \& Díaz-Morales, J. F. (2016). Problematic Facebook use and procrastination. Computers in Human Behavior, 65, 59-64. doi: 10.1016/j.chb.2016.08.022 سلس

Ream, G. L., Elliott, L. C., Dunlap, E. (2013) Trends in video game play through childhood, adolescence, and emerging adulthood. Psychiatry Journal, 2013, 301460. doi: 10.1155/2013/301460 السلسلس

Rømer Thomsen, K., Callesen, M. B., Hesse, M., Kvamme, T. L., Pedersen, M. M., Pedersen, M. U., \& Voon, V. (2018). Impulsivity traits and addiction-related behaviors in youth. Journal of Behavioral Addictions, 7, 317-330. doi: 10.1556/2006.7.2018.22 الهالسلسلي

Ryan, R. M., \& Deci, E. L. (2017). Self-determination theory: Basic psychological needs in motivation, development, and wellness. Guilford Press.

Ryan, T., Reece, J., Chester, A., \& Xenos, S. (2016). Who gets hooked on Facebook? An exploratory typology of problematic Facebook users. Cyberpsychology: Journal of Psychosocial Research on Cyberspace, 10, 4. doi: 10.5817/CP2016-3-4. المالسلسلس

Satorra, A., Bentler, P. M., (1994). Corrections to test statistics and standard errors in covariance structure analysis. In: von Eye, A., Clogg, C.C. (eds.), Latent variables analysis: Applications for developmental research (pp. 399-419). Sage.

Şalvarlı, Ş. İ., \& Griffiths, M. D. (2019). The association between internet gaming disorder and impulsivity: A systematic review of literature. International Journal of Mental Health and Addiction. Advance

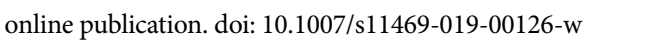

Schnauber-Stockmann, A., Meier, A., \& Reinecke, L. (2018). Procrastination out of habit? The role of impulsive versus reflective media selection in procrastinatory media use. Media Psychology, 21, 640-668. doi: 10.1080/15213269.2018.1476156 المالسلسلا

Schwartz, S. J., \& Petrova, M. (2019). Prevention science in emerging adulthood: A field coming of age. Prevention Science, 20, 305-309.

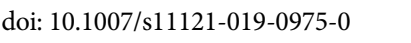

Sindermann, C., Elhai, J. D., \& Montag, C. (2020). Predicting tendencies towards the disordered use of Facebook's social media platforms: On the role of personality, impulsivity, and social anxiety. Psychiatry Research, 285, 112793. doi: 10.1016/j.psychres.2020.112793 المالسلسل

Sirois, F. M., \& Pychyl, T. (2013). Procrastination and the priority of short-term mood regulation: Consequences for future self. Social and Personality Psychology Compass, 7, 115-127. doi: 10.1111/ spc3.12011 السلسلسلس

Starcke, K., Antons, S., Trotzke, P., \& Brand, M. (2018). Cue-reactivity in behavioral addictions: A meta-analysis and methodological considerations. Journal of Behavioral Addictions, 7, 227-238. doi: 10.1556/2006.7.2018.39 السلسلس

Statista. (2017). Where people can't live without the internet. August 27. Retrieved March 9, 2020, from: https://www.statista.com/ chart/10878/where-people-cant-live-without-the-internet/

Statista. (2019). To what extent do you believe you could live without 
the internet? August 1. Retrieved March 9, 2020, from: https:// www.statista.com/statistics/989909/adults-perception-life-withoutinternet-usa/

Statista. (2020). Device usage of Facebook users worldwide as of January 2020. February 3. Retrieved March 9, 2020, from: https:// www.statista.com/statistics/377808/distribution-of-facebookusers-by-device/

Su, W., Han, X., Jin, C., Yan, Y., \& Potenza, M. N. (2019). Are males more likely to be addicted to the internet than females? A metaanalysis involving 34 global jurisdictions. Computers in Human Behavior, 99, 86-100. doi: 10.1016/j.chb.2019.04.021 البلسلسلة

Tangney, J. P., Baumeister, R. F., \& Boone, A. L. (2004). High selfcontrol predicts good adjustment, less pathology, better grades, and interpersonal success. Journal of Personality, 72, 271-324. doi:

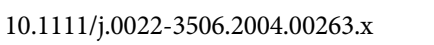

Tejeiro, R. A., Espada, J. P., Gonzalvez, M. T., \& Christiansen, P. (2016). Psychometric properties of the Problem Video Game Playing Scale in adults. Revue Européenne de Psychologie Appliquée/ European Review of Applied Psychology, 66, 9-13. doi: 10.1016/j. erap.2015.11.004 السلسلس

Thompson, S. H., \& Lougheed, E. (2012). Frazzled by Facebook? An exploratory study of gender differences in social network communication among undergraduate men and women. College Student Journal, 46, 88-98. السلسلس

Tifferet, S., \& Vilnai-Yavetz, I. (2014). Gender differences in Facebook self-presentation: An international randomized study. Computers in Human Behavior, 35, 388-399. doi: 10.1016/j.chb.2014.03.016 المالسلس

Triberti, S., Milani, L., Villani, D., Grumi, S., Peracchia, S., Curcio, G., \& Riva, G. (2018). What matters is when you play: Investigating the relationship between online video games addiction and time spent playing over specific day phases. Addictive Behaviors Reports, 8, 185-188. doi: 10.1016/j.abrep.2018.06.003 الملسلسلس

Turel, O. (2015). An empirical examination of the "vicious cycle" of Facebook addiction. Journal of Computer Information Systems, 55, 83-91. doi: 10.1080/08874417.2015.11645775 السلس السلس

Turel, O., He, Q., Xue, G., Xiao, L., \& Bechara, A. (2014). Examination of neural systems sub-serving Facebook "addiction". Psychological Reports, 115, 675-695. doi: 10.2466/18.PR0.115c31z8 الملسلسلسا .

Turel, O., \& Qahri-Saremi, H. (2016). Problematic use of social networking sites: Antecedents and consequence from a dual-system theory perspective. Journal of Management Information Systems, 33, 1087-1116. doi: 10.1080/07421222.2016.1267529 سلس

Turel, O., Brevers, D., \& Bechara, A. (2018). Time distortion when users at-risk for social media addiction engage in non-social media tasks. Journal of Psychiatric Research, 97, 84-88. doi: 10.1016/j.jpsy- chires.2017.11.014 سلس

Twenge, J. M., Joiner, T. E., Rogers, M. L., \& Martin, G. N. (2018). Increases in depressive symptoms, suicide-related outcomes, and suicide rates among US adolescents after 2010 and links to increased new media screen time. Clinical Psychological Science, 6, 3-17. doi: 10.1177/2167702617723376 المبلم

Van Rooij, A. J., Kuss, D. J., Griffiths, M. D., Shorter, G. W., Schoenmakers, T. M., \& Van De Mheen, D. (2014). The (co-)occurrence of problematic video gaming, substance use, and psychosocial problems in adolescents. Journal of Behavioral Addictions, 3, 157-165. doi: 10.1556/jba.3.2014.013 المبلسلسل

Wald, A. (1943). Tests of statistical hypotheses concerning several parameters when the number of observations is large. Transactions of the American Mathematical Society, 54, 426-482. doi: 10.2307/1990256 المالسلس

Wang, H. Y., Sigerson, L., \& Cheng, C. (2019). Digital nativity and information technology addiction: Age cohort versus individual difference approaches. Computers in Human Behavior, 90, 1-9. doi: 10.1016/j.chb.2018.08.031 السلسلس

We Are Social Inc. (2020). Digital 2020. Retrieved March 9, 2020, from: https://wearesocial.com/digital-2020

Wittek, C. T., Finserås, T. R., Pallesen, S., Mentzoni, R. A., Hanss, D., Griffiths, M. D., \& Molde, H. (2016). Prevalence and predictors of video game addiction: A study based on a national representative sample of gamers. International Journal of Mental Health and Addiction, 14, 672-686. doi: 10.1007/s11469-015-9592-8 البلسلسلس

World Health Organization (2018). International classification of diseases for mortality and morbidity statistics (11th Revision). Retrieved March 9, 2020, from: https://icd.who.int/browse11/l-m/en

Yeh, Y. C., Wang, P. W., Huang, M. F., Lin, P. C., Chen, C. S., \& Ko, C. H. (2017). The procrastination of internet gaming disorder in young adults: The clinical severity. Psychiatry Research, 254, 258-262. doi:

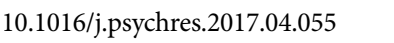

Yee, N. (2006). Motivation for play in online games. CyberPsychology and Behavior, 9, 772-775. doi: 10.1089/cpb.2006.9.772 الملسلسلة

Zhao, X., Lynch Jr, J. G., \& Chen, Q. (2010). Reconsidering Baron and Kenny: Myths and truths about mediation analysis. Journal of Consumer Research, 37, 197-206. doi: 10.1086/651257 الملسلسلس

Zhao, J., Meng, G., Sun, Y., Xu, Y., Geng, J., \& Han, L. (2019). The relationship between self-control and procrastination based on the selfregulation theory perspective: The moderated mediation model. Current Psychology. Advance online publication. doi: 10.1007/

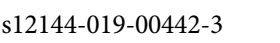

RECEIVED 05.04.2020 | ACCEPTED 18.08.2020 


\section{SUPPLEMENTARY MATERIAL}

TABLE S1.

Correlation Coefficients Between Self-Control Dimensions and Age

\begin{tabular}{|c|c|c|c|c|c|c|}
\hline & $r$ & $S E$ & $z$ & $p$ & \multicolumn{2}{|c|}{$95 \% \mathrm{CI}$} \\
\hline Female gamers & 0.21 & 0.05 & 3.95 & 0.000 & 0.10 & 0.31 \\
\hline Male gamers & 0.13 & 0.05 & 2.88 & 0.004 & 0.04 & 0.22 \\
\hline \multicolumn{7}{|c|}{ Goal maintenance, Initiative and persistence } \\
\hline Female gamers & 0.35 & 0.04 & 7.87 & 0.000 & 0.27 & 0.44 \\
\hline Male gamers & 0.23 & 0.04 & 5.45 & 0.000 & 0.15 & 0.32 \\
\hline \multicolumn{7}{|c|}{ Goal maintenance, Switching and flexibility } \\
\hline Female gamers & -0.04 & 0.06 & -0.68 & 0.496 & -0.15 & 0.07 \\
\hline Male gamers & 0.20 & 0.05 & 4.37 & 0.000 & 0.11 & 0.29 \\
\hline \multicolumn{7}{|c|}{ Goal maintenance, Inhibition and adjournment } \\
\hline Female gamers & 0.35 & 0.05 & 6.95 & 0.000 & 0.25 & 0.44 \\
\hline Male gamers & 0.30 & 0.04 & 6.98 & 0.000 & 0.22 & 0.39 \\
\hline \multicolumn{7}{|c|}{ Goal maintenance, Age } \\
\hline Female gamers & -0.01 & 0.05 & -0.22 & 0.826 & -0.11 & 0.08 \\
\hline Male gamers & -0.09 & 0.05 & -1.73 & 0.084 & -0.19 & 0.01 \\
\hline \multicolumn{7}{|c|}{ Proactive control, Initiative and persistence } \\
\hline Female gamers & 0.39 & 0.05 & 8.38 & 0.000 & 0.30 & 0.48 \\
\hline Male gamers & 0.36 & 0.04 & 8.60 & 0.000 & 0.28 & 0.44 \\
\hline \multicolumn{7}{|c|}{ Proactive control, Switching and flexibility } \\
\hline Female gamers & 0.07 & 0.06 & 1.17 & 0.243 & -0.05 & 0.19 \\
\hline Male gamers & 0.20 & 0.05 & 4.20 & 0.000 & 0.11 & 0.29 \\
\hline \multicolumn{7}{|c|}{ Proactive control, Inhibition and adjournment } \\
\hline Female gamers & 0.15 & 0.05 & 2.86 & 0.004 & 0.05 & 0.26 \\
\hline Male gamers & 0.01 & 0.05 & 0.24 & 0.813 & -0.08 & 0.11 \\
\hline \multicolumn{7}{|c|}{ Proactive control, Age } \\
\hline Female gamers & 0.11 & 0.05 & 2.24 & 0.025 & 0.01 & 0.21 \\
\hline Male gamers & 0.10 & 0.04 & 2.21 & 0.027 & 0.01 & 0.18 \\
\hline \multicolumn{7}{|c|}{ Initiative and persistence, Switching and flexibility } \\
\hline Female gamers & -0.09 & 0.06 & -1.59 & 0.111 & -0.20 & 0.02 \\
\hline Male gamers & 0.13 & 0.05 & 2.81 & 0.005 & 0.04 & 0.22 \\
\hline \multicolumn{7}{|c|}{ Initiative and persistence, Inhibition and adjournment } \\
\hline Female gamers & 0.34 & 0.05 & 7.04 & 0.000 & 0.25 & 0.44 \\
\hline Male gamers & 0.33 & 0.04 & 7.77 & 0.000 & 0.25 & 0.41 \\
\hline \multicolumn{7}{|c|}{ Initiative and persistence, Age } \\
\hline Female gamers & 0.08 & 0.06 & 1.44 & 0.150 & -0.03 & 0.19 \\
\hline Male gamers & 0.04 & 0.05 & 0.85 & 0.394 & -0.05 & 0.13 \\
\hline \multicolumn{7}{|c|}{ Switching and flexibility, Inhibition and adjournment } \\
\hline Female gamers & -0.05 & 0.06 & -0.89 & 0.373 & -0.17 & 0.07 \\
\hline Male gamers & 0.03 & 0.05 & 0.68 & 0.499 & -0.06 & 0.13 \\
\hline \multicolumn{7}{|c|}{ Switching and flexibility, Age } \\
\hline Female gamers & -0.03 & 0.06 & -0.54 & 0.591 & -0.15 & 0.08 \\
\hline Male gamers & -0.08 & 0.05 & -1.73 & 0.084 & -0.18 & 0.01 \\
\hline \multicolumn{7}{|c|}{ Inhibition and adjournment, Age } \\
\hline Female gamers & 0.10 & 0.05 & 1.95 & 0.051 & 0.00 & 0.20 \\
\hline Male gamers & 0.16 & 0.04 & 3.60 & 0.000 & 0.07 & 0.24 \\
\hline
\end{tabular}

